\title{
UNA MIRADA SOBRE LA IDENTIDAD DE LAS CIUDADES LUSO-BRASILEÑAS. CONSIDERACIONES SOBRE EL PATRIMONIO PAISAJÍSTICO EN OLINDA Y OURO PRETO
}

\author{
Marcelo Almeida Oliveira \\ Centro de Estudos da População, Economía e Sociedade - CEPESE/Portugal \\ Instituto Estadual de Florestas - IEF/Minas Gerais/Brasil
}

\begin{abstract}
RESUMEN
Cuando nos encontramos con el patrimonio paisajístico de ciudades brasileñas como Olinda y Ouro Preto queda evidente la idea de conjunto. Esa toma de conciencia resulta de la integración generada entre los trazados de estas ciudades y las características biofísicas de los lugares donde las mismas permanecen dispuestas. Los trazados construidos se encuentran completamente sometidos por la fuerza del lugar biofísico. Así, en el tejido urbano, los espacios abiertos posibilitan la continuidad ecológica preexistente y surgen como jardines, por la dimensión emocional que proporcionan, tanto en quien habita las ciudades como en aquellos que las visitan. Aquí, podemos afirmar que el "Genius loci" está bien presente en el conjunto de estas dos ciudades.
\end{abstract}

Palabras clave: Olinda, Ouro Preto, patrimonio paisajístico, patrimonio urbano, patrimonio cultural

\section{ABSTRACT}

When we observe the landscape heritage of Brazilian cities such as Olinda and Ouro Preto, the idea of an architectural ensemble is very clear. This awareness comes from the integration generated in the layout of such cities and the biophysical characteristics of the sites they are placed. The built layouts are totally dominated by the strength of the biophysical site. Thus, in the urban mesh, the open spaces enable the preexisting ecologic continuity and come up as gardens, through the emotional dimension they offer, either for those who live in the cities or for those who visit them. We can assert that the "Genius loci" is truly present in these two cities.

Keywords: Olinda, Ouro Preto, landscape heritage, urban heritage, cultural landscape

\section{Contextualización}

En la actualidad, cada vez es más patente la falta de conocimiento acerca de las tradiciones heredadas. En las ciudades brasileñas, los espacios abiertos, sobre todo los de carácter privado, han sido tratados como anexos de las edificaciones, pedazos de tierra sobrante que no fueron desmembrados y ocupados o como intervenciones despegadas de un determinado contexto cultural o aún como si fueran meros paños de fondo para la conservación escénica de monumentos arquitectónicos, principalmente los de reconocido valor artístico e histórico. Es como si nada pudieran expresar además de la función de marco que les cabe. La naturaleza recreada en los jardines, en las huertas y en los pomares es entendida habitualmente como si estuviera congelada en el tiempo, desvinculada de cualquier proceso de construcción del paisaje y de su relación con los antiguos moradores. En general, huertas y pomares no son entendidos como manifestaciones culturales de valor patrimonial.

No menos grave es el equívoco de creer que las manchas verdes pueden ser evaluadas solamente a partir del levantamiento topográfico, botánico y catastral. La insistencia en proseguir las referidas razones influye en la continuidad de una situación de cuasi torpor ante la ocupación clandestina que incide sobre estos lugares. 
En relación a esto, prácticamente no está nada hecho para contener la vigencia de los intereses privados, que es resultado de la descaracterización y fragmentación de antiguos sistemas de producción, que aún forman parte de la malla urbana. El avance de este proceso ha repercutido en el desequilibrio y en el debilitamiento de componentes esenciales, culturales y ecológicos del patrimonio paisajístico.

Muchas informaciones que podrían ser elucidativas sobre los jardines luso-brasileños se perdieron, debido a las sucesivas depredaciones ocurridas en los conjuntos arquitectónicos, otras se encuentran dispersas por archivos y bibliotecas, pero lo importante es comprender que, además de registros históricos, existen caminos alternativos que pueden suplir las lagunas de conocimiento. A través de la observación de culturas compartidas entre Brasil y Portugal, es posible identificar concepciones, valores, visiones de la naturaleza que influyeron en la creación de espacios abiertos.

Es por medio del establecimiento de parámetros comparativos y de la realización de asociaciones mentales, con base en experiencias en los dos mundos, que poco a poco el hilo de la memoria será fortalecido y recuperado, y consecuentemente lo que no era debidamente comprendido podrá ser corregido y relacionado a una misma génesis, como es el caso de los espacios abiertos $\mathrm{y} / \mathrm{o}$ del patrimonio paisajístico, tema este que gana sentido al ser apreciado a partir de la cultura ancestral. El valor cultural identitario que hoy reconocemos en el paisaje y que se observa en los relatos de muchos cronistas estudiados por nosotros es completamente desconocido y por eso ignorado, sobre todo, por quien tutela las ciudades luso-brasileñas.

Así, el conocimiento de los orígenes, por la lectura interpretativa de los hechos, se hace importante. Nos permite redescubrir la propia identidad, lo que nos sitúa ante prácticas y saberes que fueron utilizados en el diseño del paisaje. De ahí que entendamos y valoremos la permanencia del tejido verde en el medio urbano. En líneas generales, puede ser comprendido a partir de esquemas morfológicos y tipológicos, definidos mediante la relación entre espacios abiertos y edificados, entre elementos vivos e inertes. Además de eso, el modo como las pequeñas parcelas o las unidades agrícolas constituyeron la forma de los primitivos poblamientos, también, nos lleva a reflejar sobre el tipo de ocupación y el aprovechamiento de los recursos potenciales en cada sitio.

En ese cuadro, jardines, huertas y/o pomares, además de ser lugares de producción, proporcionaban ocio a sus usuarios. Eran lugares significativos que ayudaban a amparar la memoria colectiva, contribuyendo a la mejora de la calidad de vida y a la sociabilidad en los aglomerados urbanos, como sucede hasta la actualidad. En la parte alta de Olinda, por ejemplo, el macizo verde llega a ser exuberante. Está conformado por muchos cocos y grandes árboles frutales, conocidos como fruteiras, de alturas variadas y con amplias y densas copas, que proporcionan condiciones de estabilidad en sus sombras, casi nocturnas. Constituyen uno de los principales componentes de los espacios abiertos. Dichos árboles permiten abrigo a los habitantes del lugar que, popularmente, los toman como parte de la propia casa. Según testimonios recogidos "in loco", antiguamente la vida acostumbraba a ser más bulliciosa en estos lugares, donde las familias se reunían para conversar acerca de asuntos cotidianos, para confraternizar con los amigos en ocasiones especiales, realizar tareas del día a día e incluso donde los niños jugaban a ser niños, corriendo por entre los troncos de los árboles y subiendo de rama en rama, a fin de coger y saborear cuántos frutos pudieran coger o comer.

El verde urbano en Ouro Preto, por su parte, se presenta de manera diferenciada, menos suntuoso, pero no por eso menos envolvente y sensual. En esta ciudad, aún existen huertas y/o jardines. El cultivo de cítricos sobresale como valor tradicional de la cultura del lugar, siendo uno de los rasgos de herencia portuguesa en el paisaje, aunque ahora es menos numeroso. La producción de subsistencia era desarrollada en los dominios de las viviendas, en pequeñas parcelas de terreno agrario, formalizadas a partir de componentes culturales y naturales, que propiciaban condiciones específicas de tiempo libre.

En lugares como los mencionados se manifestaba el ocio. El término en sí fue mal inter- 
pretado por extranjeros y por la propia historiografía. Comúnmente se percibía el citado estado de espíritu por medio de la imagen de la pereza, por demás reductora para justificar el comportamiento de los usuarios de los espacios abiertos. Ante los atributos de la naturaleza, las personas se rendían instintivamente al ambiente local, donde las sensaciones eran despertadas y los sentidos estimulados, principalmente, en periodos de cosechas, cuando los frutos podían ser recogidos y/o saboreados a los pies de árboles y arbustos. Podemos decir que las situaciones de tiempo libre, ocio, placer y/o recreo formaban parte de la misma realidad que los lugares orientados a la producción de subsistencia. Así, se cultivaban determinadas especies vegetales, valoradas por sus calidades estéticas, o incluso se construían determinados artificios, como: jardineras, pozos de agua, parras, tanques de ornamento y riego, que hacían atractivos los jardines, las huertas y los pomares.

Generalmente, los relatos históricos de naturalistas y/o viajeros extranjeros, elaborados durante el siglo XIX, fueron poco elucidativos en cuanto a la descripción de las parcelas verdes urbanas. Las narrativas se fundamentaban en un enfoque discriminatorio, a partir de concepciones ajenas a los patrones culturales que describían. Así, las referidas parcelas no eran entendidas, lo que nos lleva a reevaluar críticamente el contenido de las crónicas de la época. Belleza y utilidad, placer y trabajo, formaron parte de la existencia de los espacios abiertos insertados en la malla urbana. Además de ser lugares organizados para el desempeño de actividades de subsistencia, también eran espacios de tranquilidad cuyos componentes presentaban finalidad emotiva o recreativa. La propia imagen de la ciudad tradicional reforzaba el referido aspecto, a través de la contigüidad y de la continuidad de los espacios abiertos. Los conjuntos constituidos también expresaban una determinada vivencia de la naturaleza, proseguida por diversos segmentos de la sociedad.

\section{El carácter de los lugares}

Algunos núcleos clasificados o inventariados, fundados en el periodo colonial, todavía conservan rasgos que son dignos de ser resalta- dos para que comprendamos mejor la identidad que los individualiza y los hace tan especiales. Los respectivos patrimonios aún mantienen una estrecha sintonía con el paisaje, hecho que puede ser observado por medio de la morfología y de las tipologías existentes. En este sentido, reforzamos la importancia de ciertas peculiaridades en el diseño de la ciudad tradicional, entre las que sobresalen: la presencia relevante del espacio vacío, la constitución de espacialidades agradables, la implantación de referencias arquitectónicas en lugares de destaque, el fomento de los cultivos de subsistencia por medio de la conservación de las parcelas hortofrutícolas, el respeto por las líneas dominantes del relieve. Este modo de ocupar el suelo contribuye a impregnar los tejidos urbanos de valores culturales, humanos y simbólicos, los cuales se han visto reducidos en las últimas décadas debido a las construcciones aleatorias y clandestinas (Figs. 1 y 2).

Buscaremos, también, plasmar aspectos figurativos y cualitativos de la forma urbana a partir de cuestiones funcionales. El análisis de la ciudad bajo este punto de vista contribuye ciertamente al conocimiento y a la valoración de los tejidos verdes. Los elementos figurativos son aquellos que facilitan la comunicación estética, despiertan la conciencia crítica de los observadores, haciéndolos más susceptibles a la comprensión del patrimonio paisajístico, inclusive en relación al contexto de una época'. Así, deben ser comprendidas las tipologías del tejido verde, una vez que permiten poner de manifiesto el proceso de estructuración de las residencias urbanas tradicionales. Con referencia a la dimensión cualitativa del espacio, puede ser entendida a partir de componentes y sensaciones relativas a la comodidad, a la protección, al refugio y a la seguridad que un determinado lugar proporciona a sus usufructuarios².

Estas impresiones son indicativas del nivel de comodidad y satisfacción proporcionado por los lugares habitados. En los asentamientos coloniales, por ejemplo, se valoraban las parcelas hortofrutícolas, no solo por la producción para la subsistencia, sino también por el hecho de reforzar la privacidad de la vida doméstica y facilitar el descanso. En el espacio urbano, eran 


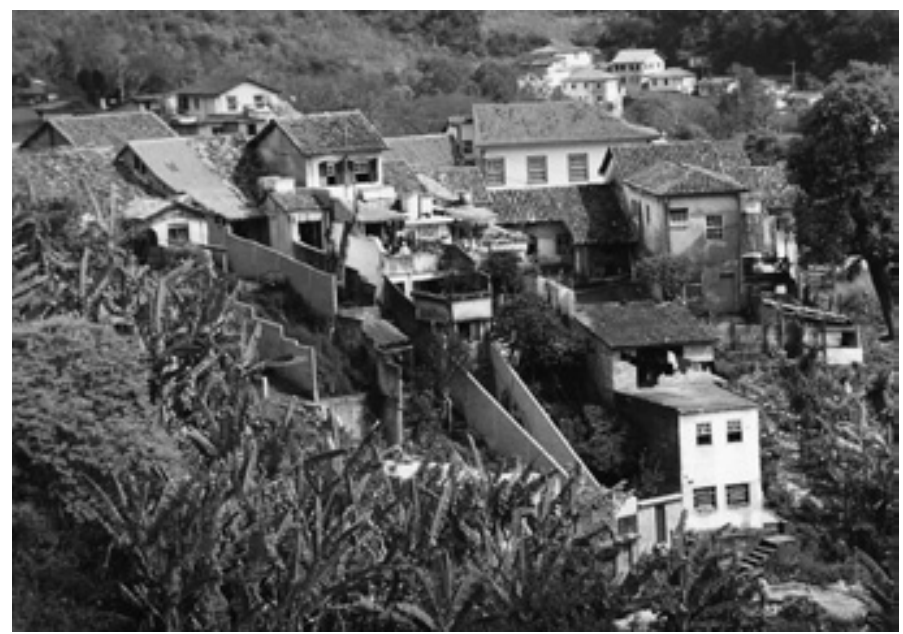

Fig. 1. Ocupación aleatoria y/o clandestina en Ouro Preto, Minas Gerais, sudeste del Brasil. 2006. Todas las fotos del artículo son del propio autor.

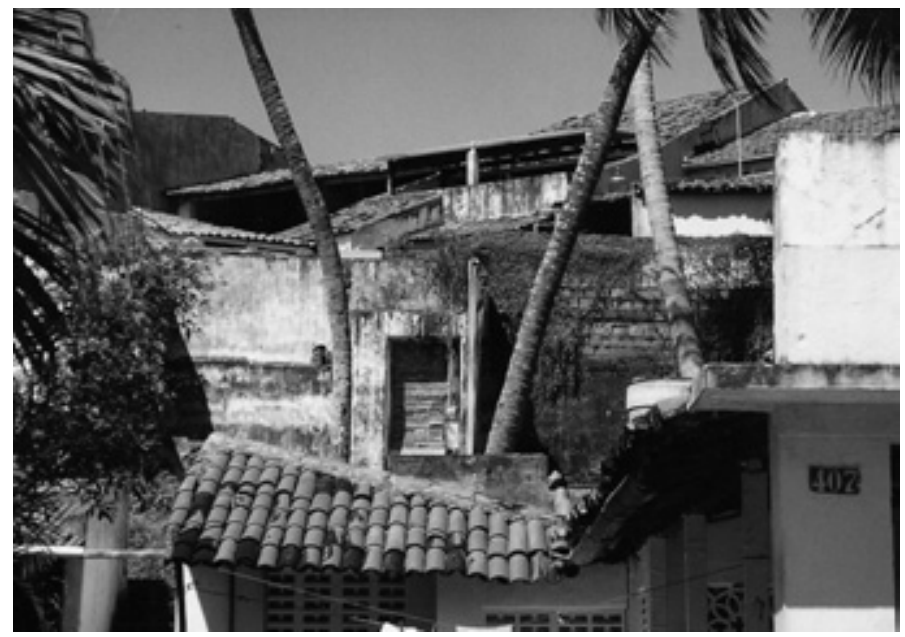

Fig. 2. Ocupación aleatoria y/o clandestina en Olinda, Pernambuco, nordeste del Brasil. 2005.

destacados los aspectos relativos a la amenidad, dimensión aromática, frescura, sonoridad y tactibilidad. Por eso, consideramos los espacios abiertos, el patrimonio paisajístico, como parte indisociable del valor cultural, del histórico y del patrimonial de las dos ciudades estudiadas 3 .
En líneas generales, el paisaje de la ciudad colonial se mostraba como un gran jardín en la mirada de sus habitantes. Identificamos, en los relatos de los viajeros extranjeros, especialmente del siglo XIX, impresiones semejantes, al tratar, con lucidez, de los conjuntos urbanos nor- 


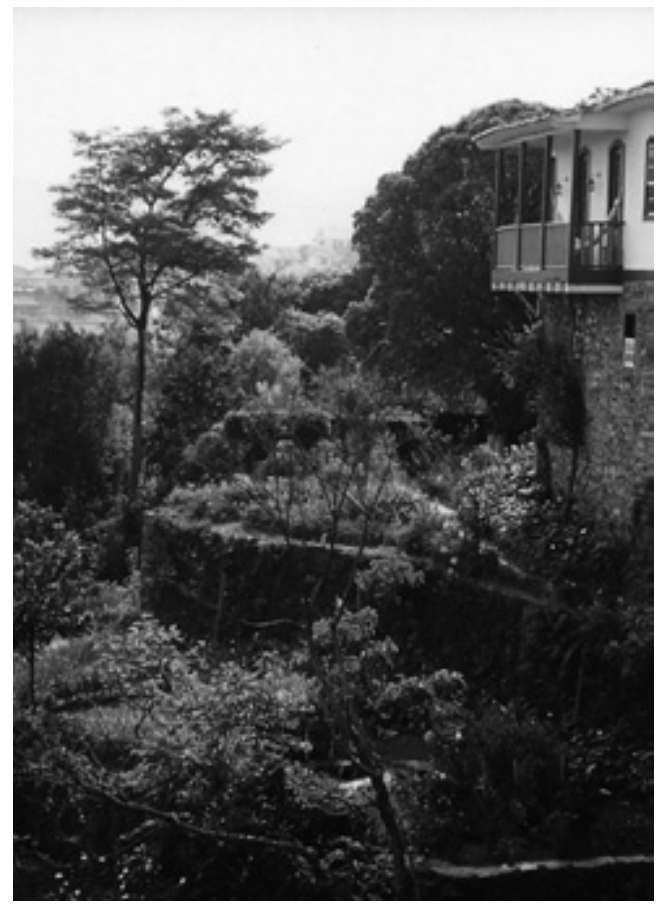

Fig. 3. Antigua terraza de cultivo en Ouro Preto. Se observa en la proximidad la presencia del balcón, 2006.

malmente organizados en sintonía con el relieve, mayoritariamente cubierto por una masa de vegetación resultante de la interacción de las parcelas hortofrutícolas (Fig. 3). Algunas narrativas, a pesar de no enlazar con detalles muy específicos, dejan translucir el encantamiento proporcionado por esa situación. El estudio iconográfico contribuye a enfatizar la pujanza de ese aspecto, sobresaliendo en el material investigado la representación del núcleo de Olinda, incluido en el manuscrito del Algemeen Rijksarchief, La Haya, c. $1630^{4}$. El referido dibujo nos permite tener una noción del ambiente predominante en el complejo edificado en relación a la disposición de elementos morfológicos, de la estructura del terreno y de las tipologías de espacios abiertos, informaciones señaladas en otro registro, el de Marin d'Olinda, c. 1630.
Aprovechamos el ejemplo de Olinda para resaltar las memorias de Joan Nieuhof, Daniel Parish Kidder y Henry Koster ${ }^{5}$.

(...) La ciudad de Olinda es construida sobre un otero: su situación, observada desde el mar, es del más agradable efecto. Iglesias y conventos que se elevan sobre los altos y los flancos de la colina, sus jardines $y$ sus árboles, sembrados aquí y alli entre las casas, dan la más alta idea de su belleza y extensión (.... ${ }^{6}$

Esta idea edénica también fue tratada por Michel Parent (1967), consultor de la UNESCO, al defender la preservación del primitivo asentamiento de Olinda, declarado "Patrimonio de la Humanidad" en 1982'. 
Olinda es una de las joyas de Brasil donde se componen admirablemente el paisaje marino y la ciudad artística rica en aproximadamente veinte iglesias barrocas $y$ un gran número de casas antiguas vivamente coloreadas. Es esto lo que impresiona en Olinda, que, por coincidencia de felices circunstancias, aunque a buen seguro provisional si no se interviene inmediatamente, el sitio está todavía intacto. (...) En Olinda, la arquitectura fulgura entre los esplendores de la naturaleza tropical. El océano aparece al fondo de este cuadro por detrás de los campanarios y palmeras. Entre las callejuelas, la vegetación ubérrima invade la colina. Este aspecto distendido de la trama urbana debe ser absolutamente preservado. Olinda no es una ciudad, es un jardín desmesurado de obras de arte, y que no cesa de polarizar y de perseguir la imaginación de los artistas. ${ }^{8}$

El empleo del vocablo jardín para designar la referida ciudad es bastante significativo. Esta percepción a nuestro ver, refuerza la condición de lugar apacible, propicio a nuevas experiencias de ver el mundo, a través de los sentidos, además del dominio de la racionalidad. Para que comprendamos mejor esta dimensión del paisaje, debemos reconocer que determinados elementos, considerados livianos son tan fundamentales como los componentes físicos de la forma urbana. El orden, en la ciudad colonial, observado a partir de la integración entre la estructura cultural y ecológica, nos ayuda a percibir mejor esas particularidades, conectadas a la dimensión sensitiva del espacio (Figs. 4 y 5).

Bajo ese aspecto, demostramos que las parcelas hortofrutícolas insertadas en el tejido urbano continúan siendo evaluadas, en esencia, como jardines o lugares amenos y secretos, por ampliar la capacidad perceptiva de sus usuarios, dotándolos de mayor conciencia en relación al espacio que habitan, así como descrito en relatos inaugurales.

El paisaje debe ser entendido, estudiado, a partir de una metodología inductiva, lo que necesariamente envuelve la comprensión de las relaciones y de las interrelaciones entre la estruc- tura cultural y la estructura ecológica de un determinado lugar?.

Los componentes de la estructura cultural se refieren a los sistemas antrópicos en el paisaje. Normalmente, se fundamentan en concepciones estéticas, económicas, socio-culturales, relacionadas con valores propios de una época, que acaban incidiendo en la regulación de patrones de ocupación y uso del suelo y en la difusión de morfologías y tipologías específicas, concernientes al modo de construir y habitar el espacio. En las ciudades coloniales, estas realizaciones estaban eminentemente vinculadas a las particularidades biofísicas de los respectivos sitios, o sea, había una continuidad de la forma urbana en el medio natural, que se mantenía en equilibrio con el clima, la geología, el relieve y el suelo de cada lugar, de manera correlativa e interdependiente, estableciendo la base de un complejo ecológico.

\section{Componentes naturales}

\subsection{Clima}

En el dominio de la ciudad, se entiende el clima como resultado de múltiples factores, fuertemente asociados a los elementos morfológicos y al tipo de material y revestimiento de las respectivas superficies, y que acaban interfiriendo en diversos fenómenos, entre ellos: los efectos de absorción, almacenamiento térmico y reflexión de la radiación solar, la trayectoria y velocidad de los vientos, la variación de la composición atmosférica, la evaporación y la tasa de humedad relativa del aire ${ }^{10}$.

La comprensión de la forma urbana, por medio de una mirada holística, nos posibilita evaluar la ciudad, en particular los núcleos clasificados, a partir de la dimensión vivencial, estrictamente marcada por la presencia de elementos ecológicos y morfológicos. Destacamos aquí el aspecto climático, muchas veces asociado a la difusión de los "miasmas pestíferos", durante el periodo Brasil-Colonia. En Ouro Preto, por ejemplo, se combatían tales emanaciones mediante un mayor cerramiento de los edificios, evitándose la acción del viento y de la humedad en la vivienda local ${ }^{11}$. Sin embargo, en lugares calientes como Olinda, el uso de los balcones estaba 


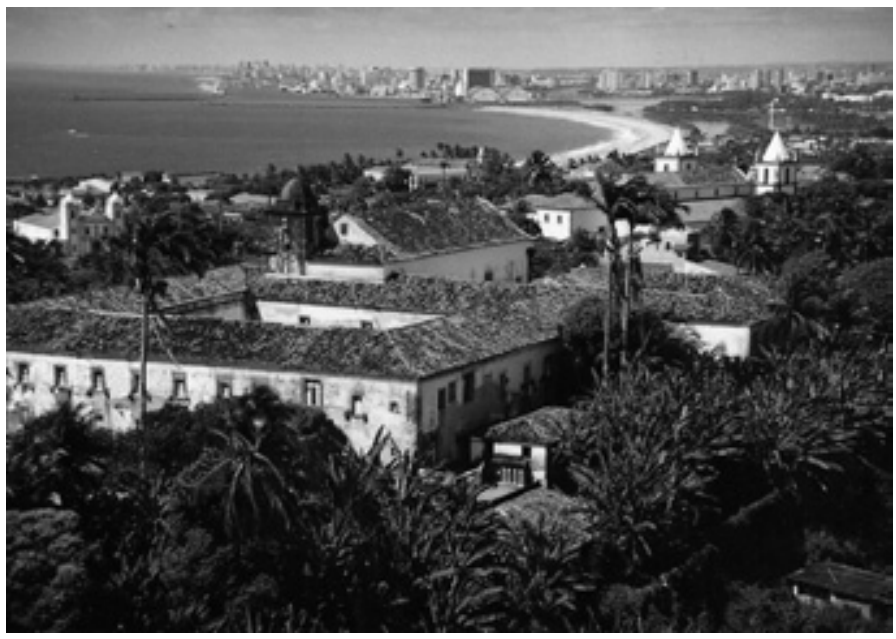

Fig. 4. Vista panorámica de Olinda. En primer plano, antiguo conjunto jesuíta, actual Seminario Archidiocesano, 2005.

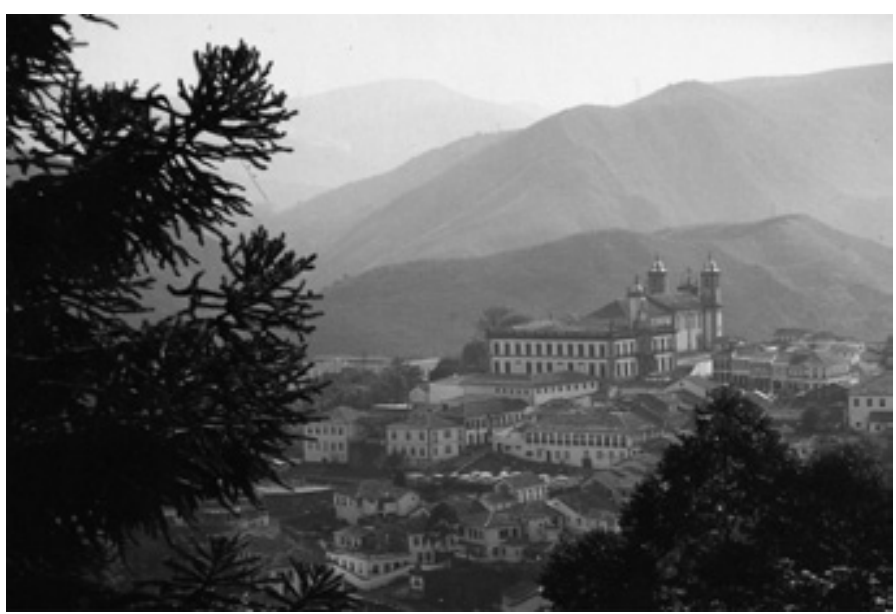

Fig. 5. Vista panorámica de Ouro Preto, Solar de las Lajes, 2006.

vinculado a la noción de comodidad y salubridad, lo que estimulaba el contacto de sus usuarios con los jardines.

Entre los parámetros fundamentales del clima, resaltamos aquellos que se hacen evidentes en el diseño de huertas, pomares o jardines, lo que nos permite establecer analogías entre diferentes realidades. En Portugal, destacamos que el espacio productivo era moldeado por un sistema de riego concebido según un trazado geométrico, resultando de ese trazado parcelas estrictamente regulares y proporcionales entre $s^{12}$. En Brasil, por su parte, como bien recuerda el Padre Fernão Cardim (c.1584), en sus apuntes, el "cielo" siempre "hacía llover", justificando la poca utilidad de la fuente, del pozo y del 
tanque, incluidos en los dominios de la huerta del colegio jesuita de Olinda. No obstante, a pesar de la benignidad del clima local, estos recursos eran bienvenidos y necesarios, sobre todo en épocas de estiaje, ayudando a mantener los naranjos y los otros cultivos, especialmente a partir de sistemas hidráulicos menos aparentes, en subespacios menos geometrizados ${ }^{13}$.

Las huertas/pomares y los jardines se hallaban articulados en sistemas de derivación de agua, conforme a lo observado en el antiguo Seminario de Nossa Senhora da Boa Morte, vecino al Palacio del Obispo, en la ciudad de Mariana. El agua captada en el patio interno del referido complejo era dirigida a canalones y tanques situados en la huerta, cultivada al lado de uno de los alzados del edificio. Había toda una lógica en el aprovechamiento y en la distribución del recurso hídrico, hecho igualmente verificado en otro conjunto, el del Convento Franciscano de Olinda, donde se recogía de la misma manera el agua de lluvia para el abastecimiento de la cisterna, construida en la terraza contigua al claustro. El recurso captado servía no solo para el riego del pomar, dispuesto en un plano de nivel inferior, sino también para abastecer las necesidades cotidianas de los congregados.

En los primitivos núcleos de Olinda y Ouro Preto, también es posible observar, en el interior del tejido urbano, la asociación establecida entre el tipo de clima existente y la cubierta vegetal, algo que influye fuertemente en la idea de vivienda en esos lugares. Así, se hace prudente comentar que el término quintal puede tener significados muy cercanos, pero con matices distintos, explicitando la riqueza cultural existente en un país con dimensiones continentales como Brasil. De acuerdo con los testimonios recogidos en Ouro Preto, los quintais se destinaban básicamente a actividades productivas, pudiendo eventualmente proporcionar ocio a los usuarios por medio del descanso o de la contemplación de vistas panorámicas enriquecidas por aromas, sabores, sonidos, tactibilidades y otras cualidades fundamentales, normalmente observadas en esos recintos. El diseño del quintal se basaba en el orden del siguiente repertorio de elementos: depósitos y/o talleres, tanques de almacenamiento de agua, terreiro contiguo a eras de hortalizas cuyas especies se mostraban dispuestas, como de costumbre, en una irregularidad desordenada. Estos complejos también se encontraban marcados, aleatoriamente, por diversos frutales. En cuanto al terreiro, lugar abierto en la proximidad de la cocina, su cuidado se mantenía con una limpieza constante, lo que incluía el barrido y cepillado del piso de tierra batida. Era el lugar donde los niños acostumbraban a estar. No había necesidad de protegerse de los excesos de radiación solar, como en Olinda. En relación a los límites de los terrenos, eran demarcados por medio de muros bajos y/o de contención de piedra seca unida, que reforzaban las sensaciones de bienestar, intimidad y seguridad. Estos lugares se mostraban como ambientes abiertos e iluminados, donde las mínimas intervenciones se justificaban, sobre todo, por razones práctico-utilitarias, entre ellas, las de mejoría de la calidad del suelo, con el constante reciclaje de materia orgánica producida "in loco"14.

En cuanto a la presencia de los recursos hídricos, algunos quintais aún poseen sus propias fuentes, hecho asociado a la localización de las viviendas en las partes bajas de laderas con barrancos y a las condiciones climáticas específicas de la región. En el pasado, en situaciones menos favorables, el abastecimiento cotidiano era hecho por trabajadores manuales. El acceso de los esclavos a la vivienda era independiente, localizado en la parte posterior de la residencia, junto a las huertas, llegándose a él por las vías auxiliares de servidumbre (pasajes, calles y callejones). En general, en los quintais había recipientes o tanques de piedra para el almacenamiento del agua, dirigidos al auxilio de las necesidades domésticas. Sin embargo, no todas las casas disponían de esos dispositivos ${ }^{15}$.

Con referencia a los quintais de Olinda, tienen otro tipo de espacialidad, proporcionada por la disposición espontánea de frutales de gran porte en el tejido urbano, que minimiza los excesos climáticos, en particular, las altas temperaturas. La cobertura vegetal que reviste ciertos tramos del núcleo primitivo acentúa con exuberancia la noción de conjunto paisajístico del lugar, creando la sensación de continuidad del tejido verde, vista desde algunos miradores, como las plazuelas de la iglesia de San Salvador del Mundo (la catedral de Olinda), de la iglesia 
de la Divina Gracia (el antiguo colegio jesuita) y del Convento Franciscano de Nuestra Señora de las Nieves ${ }^{16}$. No podemos dejar de señalar, a partir del estudio iconográfico, el aumento del porte de la vegetación a lo largo del tiempo, lo que supuestamente habría comenzado entre el final del siglo $X I X$ y el inicio del $X X^{17}$. Esto no quiere decir que anteriormente no se hubiera dado la difusión de árboles frutales. Presumimos que la mencionada dispersión siempre se dio, debido a los beneficios generados, entre ellos, las sombras aseguradas por las copas o incluso la abundancia de frutos. Tal vez los pomares hayan dejado de ser conservados o hayan sido blanco de nuevas costumbres incorporadas por los habitantes, dando como resultado la distinta presencia del estrato arbóreo en el paisaje ${ }^{18}$.

El referido aspecto constituye una de las características más sobresalientes de la ciudad patrimonial, vista todavía como un extenso pomar, dada la contigüidad de los quintais, donde las copas de los frutales permanecen imbricadas unas en las otras. Destacamos las palabras de la residente Marília de Andrade Luna: "Veo verde y más verde desde el balcón de mi cuarto, que desagua en el mar"19. En ese conjunto, los quintais pomares son constantemente valorados por las sensaciones de placidez y solaz, resultantes principalmente del microclima proporcionado por la cobertura vegetal. De entre los beneficios generados por las manchas verdes del lugar, sobresalen: la mayor absorción del sonido, el aumento de la tasa de evapotranspiración, que incide en el descenso de la temperatura en la proximidad del suelo, la contención de las fluctuaciones y de los fuertes vientos, la filtración del suelo, la reducción de la incidencia solar en los edificios, una vez que la capacidad reflectiva de la vegetación es mínima. También destacamos el papel de la vegetación en la contención de procesos erosivos y en el enriquecimiento del suelo orgánico en el medio urbano, sobre todo en el paisaje de Ouro Preto, donde el declive tiene mayor expresión que en Olinda ${ }^{20}$.

En suma, los pomares configuran lugares aromáticos, tranquilos, fértiles, frescos y sosegantes, propicios a los descubrimientos y experiencias, siendo considerados frecuentemente verdaderos jardines, aspecto que igualmente comprende las huertas. El pomar, por la mayor verticalidad de sus árboles y proyección de sombras densas, es tratado como ambiente donde predominan sensaciones conectadas al encantamiento, al éxtasis, a lo sublime ${ }^{21}$. Esos ambientes son considerados como símbolos de constancia, donde las temperaturas permanecen agradables si son comparadas a las de las huertas, más sujetas a las intemperies del tiempo.

En Olinda, constatamos el gusto de sentir la espacialidad de los quintais, costumbre que, sin embargo, se hace cada vez más limitada. En el universo de los moradores locales, destacamos los artistas que pasaron a residir en el núcleo primitivo, sobre todo, después de la década de 1960. Acostumbradas a los valores de la cultura tradicional, esas personas demuestran tener respeto y sensibilidad por la causa de la conservación de la cobertura vegetal de la ciudad. La mayoría de ellas aprendió a convivir con las huertas y los pomares cuando aún eran niños, en los ingenios de caña de azúcar de la región, como sucedió con Genoveva Alves Días:

Mi trayectoria de vida está asociada al afecto que tengo por la naturaleza. Estuve muy dedicada al plantío. Adoro sembrar y acompañar el nacimiento de lo verde. Siento mucha energía en el contacto con todos los seres vivos. En mi mundo, siempre daba buenos días a todos ellos. Fui criada en Timbaúba, en un lugar del ingenio de Jussara Grande, en la Zona del Bosque pernambucano, lugar de tierras fértiles, de suelo adobado por el antiguo bosque. La sensación que tenía cuando andaba por el pomar de la casa grande era la mejor posible. Paseaba por entre los árboles, que alimentaban mi cuerpo $y$ espíritu. Fue de ese modo que aprendí a dibujar figuras de muñecas, con espina de naranjo, en hojas de bananeras. Fue un tiempo exquisito (...). ${ }^{22}$

Estas informaciones son relevantes por el hecho de demostrar que los referidos residentes están envueltos en la causa de la preservación del propio patrimonio. 
En este punto del artículo, intentaremos comprender principalmente como el clima, juntamente con las cuestiones culturales, influye en los aspectos inmateriales del paisaje, asunto poco estudiado en el ámbito de los núcleos patrimoniales brasileños, temática intrínsecamente asociada a la relación emotiva que algunos propietarios o residentes poseen con esos lugares. Para eso, intentamos basarnos en nociones desarrolladas por Nuno Mendoça, en su obra Para uma poética da paisagem: a ideia (1989), que trata de la dimensión cualitativa y vivencial del espacio.

Así, entender las huertas, los pomares o los jardines del tejido urbano no puede ser reducido al análisis botánico de las especies vegetales que lo componen. Es algo más complejo. Esta cuestión comprende el estudio tanto de los componentes físicos (color, dimensión, estructura, textura, volumen) como de los elementos casi imperceptibles (luz, olor, frescor, sabor, sonoridad, tacto, vista), que resultan de la relación o de la interrelación entre los componentes morfológicos del espacio ${ }^{23}$.

Tratar esta cuestión nos permite establecer comentarios y reflexiones sobre la manera como la gran mayoría de los viajeros que recorrió Brasil durante el siglo XIX se posicionaba ante la dimensión cualitativa de los espacios abiertos de los núcleos coloniales. Los extranjeros, una vez confrontados con la inmensa mezcla y variedad de elementos, inherentes a los lugares visitados, dudaban en aceptar pacíficamente el descubrimiento de lo nuevo, o sea, de los códigos culturales todavía poco asimilados. El contacto con el mundo nativo, en general, era acompañado de controversias y extrañamientos.

Bajo las miradas críticas y prejuiciosas de los viajeros, se observaban huertas, pomares o jardines como lugares confusos, desordenados $y$, en algunas situaciones, exóticos. Cuando se interesaban en describirlos, las escenas observadas se hacían más reales. En ese caso, se clasificaban y se enumeraban las especies de valor alimentario, condimental, medicinal y ornamental, poniéndose de manifiesto siempre aquellas variedades que podrían ser utilizadas como productos económicos. Raramente, en la óptica de los naturalistas, se referían a las parcelas hortofrutícolas como lugares de relieve en el conjun- to de los pueblos y ciudades. Eran normalmente evaluadas a distancia. La visión era el principal sentido usado por el observador ante el paisaje observado.

Sin embargo, era y continúa siendo diferenciado el modo en como los propietarios acostumbran a interactuar con la propia vivienda. Basta decir que algunos de los habitantes de los lugares estudiados aún mantienen fuerte apego a los jardines. Estos recintos permanecen como testimonios de una naturaleza pululante y patrimonial, lo que nos ayuda a identificar antiguas costumbres y correctos componentes morfológicos, facilitándonos aun la realización de comparaciones entre los conjuntos paisajísticos de las ciudades patrimoniales, mínimamente protegidos, aspecto destacado en el testimonio de Ana Amélia de Oliveira, acerca de la gradual descaracterización del patrimonio urbano de Ouro Preto.

Los espacios verdes en la ciudad tienen una importancia mayor. Resaltan la sinuosidad de los caminos, a través de vacíos, llenos de verde y vida. Últimamente, estamos perdiendo el diseño de la ciudad. La ladera de Santa Efigênia es el ejemplo más evidente de lo que ha sucedido. Ouro Preto está hinchando, engordando, volviéndose un círculo, un balón. Eso para mí es lamentable! (...). ${ }^{24}$

\subsection{Aroma}

Apreciar un jardín no se restringe al dominio de la visión, requiere percibirlo de otras maneras, incluso a través de los olores, que le son peculiares. Las brisas cargadas de aromas exhalados de cada planta, por sus flores y frutos, y por la propia tierra despiertan en nosotros sensaciones que se transforman en imágenes cognitivas y recuerdos, archivados en nuestra memoria afectiva. El olfato es una de las puertas de acceso a la comprensión de la esencia de los lugares habitados. Contribuye a la comprensión del carácter mutable del paisaje, que varía a lo largo del día y durante los ciclos anuales ${ }^{25}$.

En las ciudades patrimoniales, con referencia a ese punto, no podemos dejar de comentar el perjuicio causado por la ocupación aleatoria 
de antiguas huertas y pomares, de donde provenían algunos de los principales registros olfativos que distinguían la vida cotidiana de sus usuarios. Ese tipo de ocupación, además de perjudicar la presencia de componentes ecológicos en la malla urbana, ha provocado un gradual cambio en los patrones de la vivienda, cada vez más funcional y menos articulada con los espacios no edificados. Con base en los comentarios hechos por varios habitantes de Olinda y de Ouro Preto, observamos como determinados aromas, que ayudaban a definir el carácter en esas ciudades, han sido atenuados o reducidos, lo que se traduce en el debilitamiento del continuo cultural en los respectivos tejidos.

Ouro Preto era la ciudad de las huertas. En cada casa había una plantación de legumbres, verduras, hierbas, flores y frutas, además de la cría de animales domésticos. Muchas de las huertas tenían fuentes propias, que servían no solo para el riego, sino también como adorno. Todo eso era común. La ciudad tenía olor de tierra mojada. Era exquisito y diferente poder sentir aquel olor. Nosotros teníamos un conjunto. Desgraciadamente, vamos a vivir de saudades. Todo se está acabando (...). ${ }^{26}$

El referido aspecto es resaltado por el proceso de descaracterización de la forma urbana. Era frecuente, en Ouro Preto, sentir el aroma de la tierra mojada, típico del espacio rural, que reforzaba la idea de conjunto en términos arquitectónico y paisajístico, y enfatizaba la concepción de orden, elemental, mutante y sencilla, relativa al espacio como un todo. La atmósfera local, favorecida por la excesiva humedad del aire y por la temperatura agradable durante gran parte del año, facilitaba la dispersión de olores, que singularizaban el ambiente de la ciudad $^{27}$. Los aromas también revelaban una íntima conexión de las huertas y de los pomares domésticos con las tradiciones populares. Podemos citar el hábito de ornar y perfumar los recintos de las casas y de las capillas e iglesias con hierbas y flores aromáticas, revelando el fuerte eslabón existente entre las personas y el mundo de la producción ${ }^{28}$.
En Olinda, las fragrancias provenientes de anacardos, colonias, jazmines, madreselvas, mangos y pitangueros caracterizaban con intensidad la vida de sus habitantes. Lo que singularizaba la ciudad de antes, hoy, constituye casi un vestigio de memoria, ante las transformaciones morfológicas ocurridas en el diseño del lugar, no siempre pautadas por criterios de calidad.

Para pisar en Olinda, es necesario quitar la sandalia. Es un suelo sagrado, lo que gran parte de los habitantes no comprende. La sensualidad de la ciudad se manifiesta a través de sus olores: del carnaval, de sus quintais, de sus frutas y de sus flores. Antes, los olores de los anacardos, de los pitangueros, de las colonias, de las madreselvas y de los jazmines eran más intensos. En la actualidad, el plantío de especies típicas es poco difundido, hecho agravado con la desaparición de la vegetación de los quintais. Eso es una tristeza (...). ${ }^{29}$

Sin embargo, los olores de flores y frutos continúan siendo exhalados por la vegetación local, haciendo revivir recuerdos, principalmente aquellos conectados al tiempo de la infancia. Las imágenes olfativas son poderosas, pudiendo suscitar impresiones, sorpresas y sentimientos que celebran el amor, la felicidad, la interioridad, la intimidad, la pasión, la plenitud, la tranquilidad, o sea, la vida.

En la ciudad tradicional, es nítida la importancia del olfato como elemento de orientación en el espacio urbano. Se hace evidente como algunos habitantes acaban creando sus propias referencias, establecidas principalmente por medio de sinestesias provocadas por atributos de ciertas especies cultivadas en huertas o pomares que, incluso vedados por muros, sirven para definir y secuenciar determinados recorridos o trayectos, en la trama de los núcleos patrimoniales.

Olinda tiene muchos olores durante el año, de floraciones y frutas, de pitangueros, mangos, anacardos. Está siempre perfumada. Entonces, es algo que entraña y queda en el aire. Las plantas también marcan los 
recorridos e identifican las casas. Existe un jardín en la calle 13 de Mayo, donde tiene un pie de jasmim-banha, una trepadora bien delicada y de suave perfume. En otros lugares, existen jazmines naranjas, también bastante perfumados, que aromatizan los luga$\operatorname{res}(\ldots) .^{30}$

En la realidad de Olinda, podemos conjeturar sobre el predominio de aromas marcados por registros bajos $^{31}$, aquellos que permanecen por más tiempo en la atmósfera, destacándose el perfume de los jazmines, bastante apreciado por la población local. Los referidos ejemplares suelen ser plantados en los espacios de transición, especialmente en la proximidad de las entradas, ventanas y balcones de las residencias urbanas. De la misma forma, nos arriesgaríamos a decir que, en Ouro Preto, aún prevalecen aromas cuyas fragrancias presentan registros altos, como el del citrinos. En ese caso se volatilizan rápidamente, lo que ayuda a definir la imagen colectiva de la ciudad y anuncia momentos especiales durante el día.

\subsection{Color y luz}

Cada lugar presenta sus propias singularidades, que normalmente están asociadas a factores biofísicos, sobre todo climáticos. En el caso de los núcleos urbanos estudiados, es posible que notemos la influencia de los componentes naturales en el carácter de los respectivos conjuntos. Se considera el carácter a partir de la constitución formal del lugar ${ }^{32}$. Es aquello que lo hace distinto de otros lugares, favoreciendo el reconocimiento por parte de sus habitantes. Así, podemos resaltar, de entre otros elementos esenciales del paisaje, la importancia del color y de la luz, que concurre en la apreciación de las mudanzas atmosféricas a lo largo de las estaciones del año, de los ritmos de la naturaleza y del tiempo, y que enriquece la experiencia cotidiana del hombre, en especial, en los ambientes construidos predominantemente con la vegetación.

Se evalúa la luz tanto como radiación electromagnética, capaz de estimular visualmente a un observador, como por "claridad emitida por cuerpos celestes" ${ }^{\prime 3}$. La luz, de acuerdo con Kevin Lynch, es determinante del carácter del espacio: "puede acentuar detalles, resaltar una silueta o textura, ocultar o revelar aspectos, contraer o ampliar dimensiones" ${ }^{\prime 34}$. En referencia al color, dice respecto a la percepción del tipo de radiación electromagnética detectada por el órgano visual. También está relacionada con la propiedad que tienen los cuerpos de "absorber o reflejar la luz" 35 . De ese modo, es notorio que los habitantes de Olinda, al expresarse sobre el antiguo núcleo, destacan la luz azulada o verduzca del lugar, oriunda de los macizos vegetales, de los pomares y de las múltiples tonalidades del cielo y del mar. La consciencia de esos detalles nos permite comentar el significado conferido a los elementos naturales que se muestran bastante dinámicos y repletos de sorpresas. Este aspecto, incluso, se encuentra presente en la producción cultural del lugar, en la música, pintura y literatura, que retratan el conjunto patrimonial a partir de la mirada poética.

En Olinda, la luz predominante en el paisaje es fuerte. Revela los contrastes, la textura y la plasticidad de las formas de la vegetación y de los edificios que se acomodan sobre las ondulaciones del relieve. Son rasgos exuberantes. Sirven para describir el patrimonio local que, en palabras de Carlos Pena Filho, irradia la fuerza de la naturaleza del lugar.

\section{De limpieza y claridad es el paisaje enfrente. Tan limpia que se disuelve la línea del horizonte. Los paisajes muy claros no son paisajes, son lentes. Son iris, sol, aguaverde o claridad solamente. Olinda es solo para los ojos, no se palpa, es solo deseo. Nadie dice: es allá que vivo. Dice solamente: es allá que veo. $(. . .)^{36}$}

Por su parte, la luz en Ouro Preto, en la mayor parte del año, es menos radiante. Los colores del paisaje son tenues. El cielo aparece la mayoría de las veces cubierto por nieblas y nubes, debido a la combinación de altitud, clima y relieve de la región, lo que reduce el alcance visual a partir de algunos puntos eleva- 


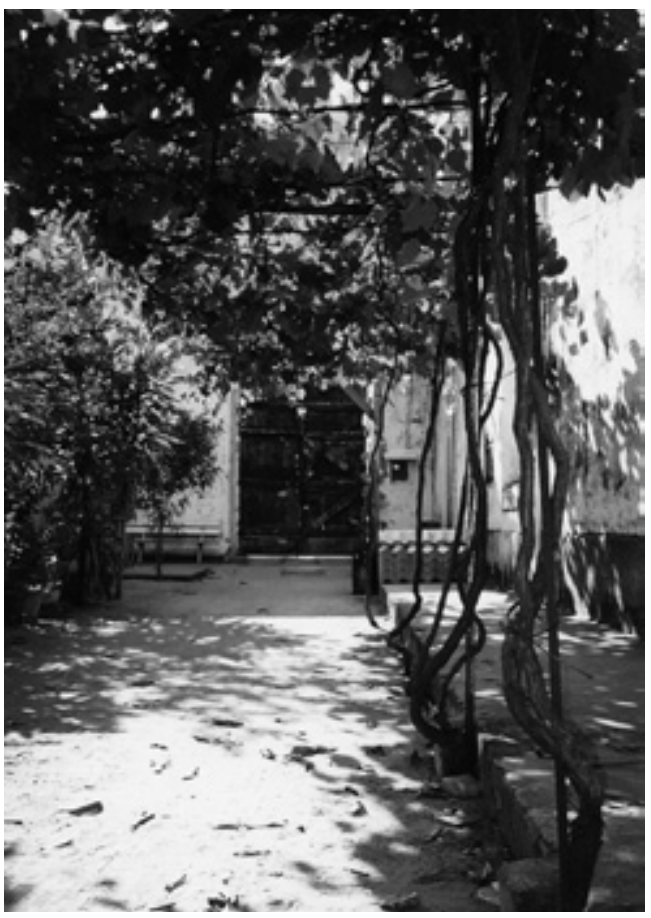

Fig. 6. Techos de sombra perfumada, Olinda, 2005.

dos de la ciudad ${ }^{37}$. En la obra de Cecília Meireles, Romanceiro da Inconfidência, encontramos un poema en que esta idea es reforzada.

He ahi la carretera, he ahi el puente, he ahí Ila montaña sobre la cual se recorta la iglesia blanca. He ahi el caballo por la verde ladera.

He ahi el soportal, el patio, y la misma puerta. (...)

Y he ahi la niebla que llega, envuelve las

mueve la ilusión de tiempos y figuras. [calles,

- La niebla que se adensa y va formando nublados reinos de saudade y llanto. ${ }^{38}$

Mientras el primitivo núcleo de Olinda se muestra como ambiente abierto y soleado, privilegiado por la localización geográfica, en un sitio de topografía ondulada en la ribera del mar, en la región Nordeste del Brasil, Ouro Preto se presenta de manera completamente diferenciada. Esta ciudad se encuentra contenida por laderas abruptas y pendientes llenas de barrancos de dos grandes sierras, la del Itacolomi y la de Ouro Preto. Esto es sobresaliente para el observador que camina por el espacio abierto. Es constantemente sorprendido por efectos de figura-fondo y luz y sombra. La luz destaca el conjunto urbano teniendo al fondo la vegetación de los quintais y la silueta de las sierras, produciéndose una diversidad de colores y formas que varía a lo largo del día y durante el año, situación que se ve perjudicada por el avance de la ocupación clandestina en las laderas de la ciudad. Esta transitoriedad del paisaje está comenzando a perderse.

\subsection{Refrigerio}

En el proceso de adaptación del hombre a la naturaleza de cada sitio, fue notable su capacidad y habilidad en la materialización de estrategias que proponían una mayor permanencia en los espacios abiertos, principalmente, en zonas climáticas favorables. En las ciudades coloniales brasileñas, la sombra de los recintos domésticos era esencial, para que sus habitantes pudieran pasar gran parte del día fuera de sus casas. En tales dominios, se valoraban determinadas costumbres, relativas al hábito de tomar el fresco, generalmente, bajo la copa de árboles frondosos, bajo el ramaje de las parras perfumadas (Fig. 6) o bajo la sombra refrescante de las arquitecturas de placer y de los balcones de las viviendas urbanas o rurales. Era patente el gusto por el refrigerio.

En el paisaje de Olinda, el clima es uno de los factores biofísicos que más condiciona el comportamiento de sus habitantes. El sol quema, principalmente en determinados horarios del día. Aunque el aire sea constantemente enfriado por brisas marítimas, los efectos de estas no son fácilmente percibidos, a no ser en lugares específicos, bajo la cobertura de grandes frutales, donde la sensación térmica, resultante de la mayor humedad relativa del aire, de la menor temperatura y de la mayor velocidad del viento, es responsable de la sensación de 
bienestar, a menudo comentada por los habitantes de esos lugares. No es pues casual que las manchas verdes, en el interior de la malla edificada, tengan el aspecto de densos pomares, mantenidos aún en secuencias continuas y discontinuas en varios tramos del paisaje.

Sin embargo, a partir del reconocimiento de Olinda como "Patrimonio de la Humanidad" (1982), se observa el avance de la ocupación de los espacios abiertos en el núcleo primitivo, fenómeno relacionado tanto con la presión del mercado inmobiliario como con la demanda impuesta por la "industria" del carnaval y del turismo, uno de los mayores vectores de crecimiento de la economía local. En este cuadro, los nuevos habitantes, orientados por conveniencias y modas, a veces impropios del lugar, quitan el carácter a su patrimonio ${ }^{39}$. Delante de estos hechos, destaca la postura de Armando de Holanda que defiende la importancia de la preservación de las tipologías tradicionales, sobre todo de la arquitectura ancestral, entendida a partir de la siguiente manera:

Trabajemos en el sentido de una arquitectura libre y espontánea, que sea una clara expresión de nuestra cultura y revele una sensible apropiación de nuestro espacio; trabajemos en el sentido de una arquitectura sombreada, abierta, continua, vigorosa, acogedora y envolvente, que, al colocarnos en armonía con el ambiente tropical, nos incite a vivir en él íntegramente..$^{40}$

Este autor trabaja con referencias asociadas a la bioclimática, con miras a la sensibilización de técnicos para la necesidad de la adecuación del proyecto arquitectónico al clima tropical, según lo que llamó el construir frondoso, basado en la noción de sombra abierta, que tiene como fin permitir el máximo posible de ventilación en las partes internas del edificio, a través de la permeabilidad a las corrientes de aire. En este sentido, la casa es concebida para mantener el mayor contacto posible con el espacio envolvente. Los balcones, que forman parte de la vivienda popular de vertiente luso-brasileña, son locales acogedores y sensuales, facilitando la convivencia sensible del hombre con los ele- mentos etéreos y físicos de los jardines o de las huertas y de los pomares.

Esta teoría del construir frondoso la encontramos de forma impresionante en muchos relatos de época. La continuidad de los hechos, observada durante nuestro proceso de investigación, nos lleva a subrayar no solo el valor ecológico, bioclimático, sino también el valor cultural que las manchas umbrosas presentan, en particular, en el tejido de la ciudad de Olinda. Es pues fundamental evaluar, inventariar y conservar tales espacios.

De aquellas dimensiones nos habla Ambrósio Fernandes Brandão, en el siglo XVII, al referirse a la belleza de los pomares o jardines en Brasil, teniendo en mente los atributos de la vegetación ${ }^{41}$. En sus relatos, son sobresalientes la hermosura de las flores y de los frutos de las pasionarias, la suave fragrancia de los curuás y el verdor de los emparrados, productivos dos o tres veces por año, que revestían las parras y ampliaban las posibilidades de modo de vida doméstico al aire libre. Este artificio proporcionaba placer, definiendo y delimitando subespacios por medio de planos horizontales que acentuaban el valor del ornamento en la estructura de los lugares de cultivo. Representaban la síntesis entre el aroma, el color y la forma, reforzando la continuidad y la impresión de espontaneidad en la organización de las parcelas hortofrutícolas ${ }^{42}$.

En otras fuentes históricas, se destaca el papel conferido a los árboles de copas densas, insertados en lugares estratégicos de los núcleos urbanos. Un hecho ocurrido entre los años 1732 y 1736 nos llamó la atención por su carácter pionero y por ser una iniciativa de religiosos benedictinos. Decía respecto al plantío de gameleiras en la plazuela enfrente al Monasterio de Nuestra Señora de la Gracia, en la ciudad de Salvador de Bahia, con el objetivo de animar el lugar ${ }^{43}$. De manera análoga, señalamos la observación del Príncipe Maximiliano de Habsburgo, hecha el año 1860, cuando, en visita a la misma ciudad, describió el gusto popular por el mango, considerado como un “(...) tesoro incalculable (...), pues se tiene la sombra y el frescor de una segunda vivienda al aire libre" ${ }^{44}$. Se destacaban tanto los mangos 


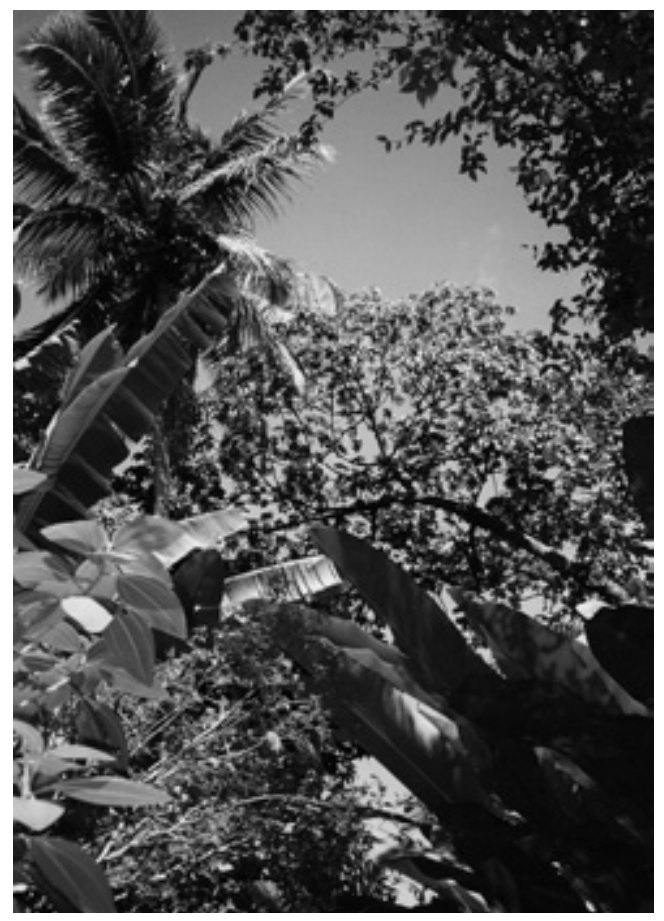

Fig. 7. Quintais pomares de Olinda, 2005.

como los árboles de jack por tener sombras "redondas", a la semejanza de un oasis de abundancia y frescura, según el escritor Joaquim Nabuco (1849-1910) ${ }^{45}$.

Son varios los ejemplos que abordan la importancia de los árboles frutales, conservados como componentes esenciales de las viviendas urbanas, permitiendo a sus habitantes el disfrute de brisas, comparadas a verdaderos soplos de vida, especialmente en lugares donde el clima acostumbra a ser tórrido. No es fortuito que las llamadas fruteiras sean consideradas diosas, por quienes convive con sus donaciones diariamente. Ganaron ese "status" debido a las múltiples funciones que les son atribuidas, entre ellas, la de proporcionar abrigo acogedor bajo sus copas, que filtran luz y calor solar (Fig. 7).

En los lugares examinados, la noción de vivienda va más allá del edificio, extendiéndose en un orden flexible, mutante y permeable, hasta el dominio de los quintais, en general dotados de atributos que varían de acuerdo con los horarios del día y las estaciones del año. El espacio bajo la copa de un frutal puede funcionar como sala de estar o como apoyo del sector de servicio, según las necesidades de sus habitantes $^{46}$. En el caso de Olinda, en diversos rincones se encuentran varias especies que forman parte de la cobertura vegetal de la ciudad, sobresaliendo: anonas, árboles del pan, carambolas, cocos, gameleiras, árboles del jack, yambos, jambolões, jenipapeiros, pitangas, pitombeiras, mangos, zapotillos, o sea, árboles de copas anchas, densas y redondas.

Al considerar el tipo de vegetación diseminado, decimos que es reflejo del gusto por vivir al aire libre. Una tendencia semejante ocurre en Ouro Preto, adaptada sin embargo a las peculiaridades del clima tropical de altitud. Los espacios abiertos acaban siendo más iluminados y 
transparentes, por el hecho de que los arbustos y los árboles tengan copas menos compactas, permitiendo mayor permeabilidad a la luz y a la visión a través de sus follajes. Al no ser necesaria tanta protección contra la radiación solar, las especies vegetales utilizadas promueven otro tipo de ambiente en la trama de antiguos jardines, no por eso menos acogedores y sensitivos (Fig. 8). Además del binomio clima/suelo, se debe considerar el aspecto cultural como determinante para la aclimatación de las plantas difundidas, lo que también privilegió la adopción de soluciones espaciales características. Estas cuestiones contribuyen a justificar la predominancia de huertas en la malla del conjunto ouropretano, lo que la hace morfológicamente distinta si es comparada, por ejemplo, a Olinda, donde predominan los pomares, como sucede en los lugares de elevadas temperaturas, en las regiones de menor altitud o más próximas de la Línea del Ecuador ${ }^{47}$.

\subsection{Sabor}

Hablar de sabor es promover un reencuentro con la propia historia. Esta temática está relacionada con las costumbres y las tradiciones, referentes a la aclimatación y a la diseminación de las especies vegetales, exóticas y nativas, que constituyeron la base de las parcelas hortofrutícolas. La preferencia por determinados alimentos, que varía de región en región, nos ayuda en la tarea de percibir las diferencias y semejanzas entre los diversos lugares. La literatura y la música registran momentos de puro deleite, asociados a la degustación de las frutas, cultivadas, incluso, en los quintais, lo que forma parte del universo de los libros de Jorge Amado y de las melodías de Alceu Valença.

Da manga-rosa quero o gosto e o sumo, Mamão maduro, sapoti, juá, Jabuticaba, seu olhar noturno, Beijo travoso de umbu-cajá. ${ }^{48}$

Los descubrimientos proporcionados por el paladar suelen impregnar la memoria de las personas. En el mundo de los recuerdos cotidianos de los habitantes de Olinda y Ouro Preto, el tiempo de la infancia está generalmente marca- do por aventuras gustativas a los pies de densos y frondosos frutales, lo que siempre se transluce en las narrativas. Lidiar con algunos de esos recuerdos nos permite comprender ciertas prácticas del proceso de difusión de plantas entre huertas y pomares.

Muchas de las especies vegetales fueron difundidas debido a sus calidades medicinales y nutritivas, además de otros atributos también considerados por la cultura vigente. Se formalizaron espacios productivos con la finalidad de suplir la subsistencia de sus usuarios, estimulando ciertos hábitos como la realización de intercambios de plantas de vivero y semillas, lo que repercutía directamente en el incremento de la biodiversidad en el medio urbano. Percibimos como los deseos y los caprichos de los habitantes, aliados al suceso de moda, influyen en la composición de las parcelas hortofrutícolas.

Hasta hoy, es común ver a los habitantes de Olinda regalándose las frutas de las especies que forman parte de los quintais, como: aguacates, acajús, carambolas, cocos, fruta del pan, guayabas, yambos, mamón, mangos, pencas de plátanos, pitangas, zapotillos. Son vistos como "frutos de la integración", por el hecho de ser deseados $^{49}$. En Ouro Preto, a su vez, la dispersión de los sabores es menos abundante, siendo reservada sobre todo a los familiares. Algunas verduras (berza, ora-pro-nóbis, taioba), así como ciertos frutos (ciruelas, plátanos, jabuticabas) aún cumplen el papel de factores de integración, estrechando lazos de amistad. Pero, se observa un desapego cada vez mayor en relación a las antiguas costumbres, como viene sucediendo en las realidades investigadas, reflejo del debilitamiento de prácticas ancestrales, conectadas a la agricultura urbana.

\subsection{Sonoridad}

En el mundo concentrado y múltiple de los núcleos urbanos, la escucha de sonoridades constituye, a buen seguro, una de las experiencias sensoriales más significativas de interacción del hombre con el espacio que lo envuelve. En diversas oportunidades a lo largo de nuestro trabajo, observamos como los sonidos son importantes en la creación de las referencias de lugar y tiempo en la memoria de los habitantes locales. En las ciudades estudiadas, en determi- 


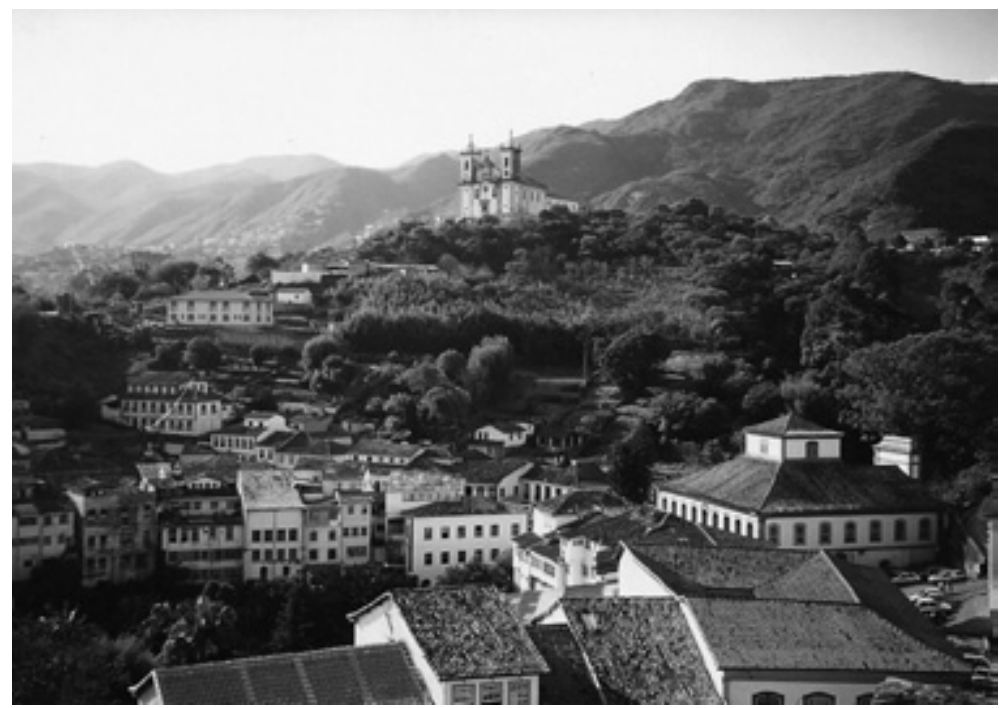

Fig. 8. Antiguos quintais de Ouro Preto, 2006.

nados periodos del año, como en la primavera y en el verano, el ambiente en las parcelas hortofrutícolas se vuelve especialmente atractivo. En esos lugares, las floraciones y las fructificaciones, además de valorar el espacio con los respectivos cromatismos, aún suelen promover eufonías oriundas de la búsqueda de alimentos por parte de animales, aves, niños e insectos, situaciones enriquecidas por el susurro de ramajes agitados al viento y, en algunos casos, por el murmullo de aguas corrientes, lo que hace especialmente apacible la vida en los quintais.

En ese universo, el canto de los pájaros está intrínsecamente asociado a la presencia de las huertas y de los pomares en el tejido urbano, donde el alimento suele ser abundante. Esta temática sirvió incluso de inspiración para la preparación de manuscritos con acuarelas relativos a la iconografía del periodo del Brasil colonial. En el material observado, se representaron ciertas aves en asociación directa con algunas especies vegetales, exóticas y nativas, alimentándose de flores y frutos, destacando: la banana, el acajú, el dendê, la fruta-do-conde, la guayaba, el mamón, la flor y el fruto de la pasionaria. Las imágenes registradas, además de reforzar la importancia de las llamadas fruteiras en la estructura de las zonas antropizadas, nos revelan el tipo de musicalidad existente en los espacios abiertos, lo que los transforma en lugares privilegiados, donde es posible desarrollar la sensibilidad y experimentar sensaciones de calma, paz y tranquilidad ${ }^{50}$.

Según Catherine Laroze, los jardines son considerados islas de felicidad y plenitud ${ }^{51}$, propicios a la escucha de los secretos de la vida, tal y como sucede en el interior de las huertas y de los pomares de Olinda y Ouro Preto. En esos rincones, el aislamiento y el sosiego son fundamentales para el establecimiento del contacto más directo con la dimensión cualitativa del espacio, despertándonos la conciencia acerca de la continuidad y de la totalidad de la forma urbana. La percepción de las sonoridades, junto con el aroma exhalado de flores y frutos, entre otros atributos de las huertas y de los pomares, nos ayuda a comprender la espacialidad de la "urbe" colonial, que no debe ser entendida solamente por medio de sus fragmentos o de los edificios preservados. 


\subsection{Relieve}

Se considera el relieve a partir de la dinámica combinada de varios factores, endógenos y exógenos en relación a la superficie terrestre, vinculados al clima, al estrato rocoso y al suelo de cada localidad o región, dando resultado en distintas unidades morfológicas ${ }^{52}$. Genéricamente, se puede hablar tanto de las formas de graduación o acumulación, caso de las planicies fluviomarinas de las pendientes de Olinda, como de las formas erosivas, igualmente señaladas en el sistema de colinas de esa misma ciudad o en las quebradas de Ouro Preto, identificadas por las crestas y escarpas presentes en su paisaje. De entre los hechos que interfieren en el modelado del relieve, se citan los procesos vinculados a los deslizamientos de las laderas, al suceso de erosiones y de inundaciones. Dependiendo de la intensidad de esos fenómenos, en el medio urbano, es necesario que el poder público tenga discernimiento y agilidad para contenerlos y reducirlos por medio de una planificación.

En el ámbito de la ciudad tradicional, se comprende el relieve como uno de los componentes ecológicos que más influye en su carácter, o sea, su forma, aspecto intrínsecamente conectado a la localización de los edificios; al ordenamiento de la estructura productiva; al trazado de la red viaria, o sea, a la concepción global de la ciudad, constituida por una red de referencias culturales, simbólicas y vivenciales. Bajo este enfoque, resaltamos la necesidad de comprensión de la preexistencia del lugar para el mantenimiento de su identidad. En los asentamientos coloniales, por ejemplo, se aprovechaban las cumbres y las laderas, a lo largo de las vías, para la creación de miradores que proporcionaban aperturas visuales y permitían la observación panorámica de los conjuntos arquitectónicos y paisajísticos, normalmente organizados en función de la existencia de los sistemas húmedo y seco. En consonancia con la lógica de ordenamiento del tejido urbano, los quintais se asociaban, preferentemente, al sistema seco, en las cumbres y laderas. Las huertas, a su vez, eran cultivadas en terrenos de topografía suave, en la proximidad de cursos hídricos. En relación a las tipologías que ocupaban parcelas de mayor dimensión, en las cercanías, como los conventos o monasterios, las casas de campo, los Jardines Botánicos y las tierras de labor, estas comprendían igualmente las laderas y las llanuras.

El relieve no solo contribuía a la implantación de las unidades productivas y recreativas, sino que condicionaba la espacialidad percibida en las citadas parcelas. La experiencia de analizar el tejido verde en dos ciudades patrimonio, Olinda y Ouro Preto, nos permite tratar con acuidad la influencia del relieve en la constitución de los respectivos patrimonios, según lo considerado en los relatos de Joan Nieuhof (1682), Auguste Saint Hilaire (1830) y Augusto de Lima Júnior $(1978)^{53}$. La presencia sobresaliente de la topografía accidentada es patente, en particular, en la realidad ouropretana, hecho observado en la disposición de ricas residencias, como demuestran los vestigios de los quintais de las casas setecentistas de Cláudio Manuel da Costa y Tomás António Gonzaga, además de los subespacios que componen los quintais donde actualmente funcionan el Instituto de Filosofía, Arte y Cultura de la Universidad Federal y la Secretaría Municipal de Educación. Los terrenos son compartimentados y distribuidos a lo largo de bancales, de modo bastante movido, al contrario de lo que sucede en Olinda, donde el relieve ondulado, menos escarpado, permitió mayor ajuste entre los subespacios de los conjuntos construidos, definiendo ambientes más armoniosos y uniformes, como todavía puede apreciarse en el dibujo de antiguas granjas y conventos. Algunas fotografías antiguas de viviendas en las proximidades del río Beberibe ilustran la mencionada situación. Se verifica esta temática a partir de dos tipos básicos de espacios, los abiertos y los cerrados, cuyas nociones sobresalen en los relatos hechos por los propios habitantes de las ciudades examinadas.

\section{Considero un privilegio poseer una casa} con quintal. Existen los quintais abiertos y los cerrados. Los abiertos permiten la visión del paisaje, de la sierra del Itacolomi, del conjunto arquitectónico de Ouro Preto. Al final de la tarde, es muy bonito ver desde el interior de ellos los contrastes de luz en las montañas, el brillo del sol dorado y el oscuro de los valles, oír el canto de los pájaros, 
sentir el olor de la naturaleza. Quedo en paz, en una soledad exquisita. (...) Los quintais cerrados son como los patios, cerrados en ellos mismos. Son más íntimos y protegidos que los otros (...). ${ }^{54}$

En el caso de los espacios cerrados, está restringida la visibilidad del interior para el exterior. Los cercados, así como la cobertura vegetal y la topografía, regulan el ambiente de los recintos, que se organizan de modo intimista y reservado, como sucede en algunos quintais de Ouro Preto, contenidos por la irregularidad del relieve, lo que reduce el contacto del observador con el paisaje del lugar. En cuanto a Olinda, el lugar tiene otro tipo de configuración geomorfológica, de aspecto menos curvado, pero identificamos ocupaciones igualmente marcadas por la reducción del campo visual, circunstancia reforzada por la densa cobertura y por el porte arbóreo de la vegetación local que forma parte del tejido urbano.

Los lugares abiertos, aunque definidos por límites, presentan otro tipo de espacialidad. En Olinda, se observan desde diversos lugares la infinitud de la línea costera en dirección a la ciudad de Recife, especialmente de aquellos posicionados en los puntos de mayor cota altimétrica ${ }^{55}$.

En Ouro Preto, de modo análogo, muchas viviendas presentan bellas vistas del conjunto urbano. Constatamos que la vida en los quintais aún favorece la convivencia de sus habitantes con el paisaje, especialmente a finales de la tarde, horario en que las temperaturas son agradables, propicias para el riego de las eras. Se trata de momentos significativos del día, cuando las personas demuestran el deseo de aprovechar el ambiente de sus huertas, generalmente asentadas en bancales. Son lugares que, provocando sensaciones de intimismo y privacidad, se acomodan perfectamente a la topografía accidentada de la región. Al recorrer varios tramos de la antigua estructura del núcleo patrimonial, en particular en las laderas de la ciudad, tenemos la oportunidad de presenciar un hecho que nos causa sorpresa, frente a la exuberancia del paisaje. La profundidad de ciertas vistas, observadas desde algunas terrazas, no nos parece ser obra del azar, por el contrario, nos lleva a pensar en las soluciones creativas, prolongando la permanencia de la mirada en el espacio. Así, destacamos la diversidad de panoramas sorprendentes, los efectos de figura-fondo y luz y sombra, que producen variaciones de colores y formas, revelando siluetas y texturas. La incidencia de la luz sobre la irregularidad del relieve, marcado por crestas rocosas, pendientes llenas de barrancos y valles encajados, influye en la percepción del paisaje, cuya imagen se hace dinámica y sensual ${ }^{56}$.

La percepción y los sentimientos inspirados por esas construcciones hacían y todavía hacen que el patrimonio paisajístico de Ouro Preto sea comparado a un gran jardín, lo que también sucede en Olinda. Es lo que se trasluce en el registro oral de algunos de sus habitantes, que demuestran el deseo de estar en y con la naturaleza.

Siempre que yo llegaba, en Ouro Preto, veía la ciudad de lejos. Era como si fuera un gran quintal. Estaba siempre plantada en lo verde. El quintal es una huerta, que tiene de todo, por lo que me trae buenos recuerdos y sensaciones. Aún consigo sentir el olor del manacá y del jazmín. El quintal está dentro de mí y nadie me lo arranca de aquí [del corazón] (...). ${ }^{57}$

No se construían las huertas o los pomares para ser observados a distancia, y sí para ser experienciados en sus múltiples manifestaciones. La mencionada manera de percibir la realidad propicia el surgimento de sensaciones y sentimientos topofílicos, que resultan de la ampliación de los límites del lugar donde se reside. Los balcones, en las residencias brasileñas, asumen un papel semejante ${ }^{58}$; además de ser lugares que promueven recuerdos, pensamientos y sueños, amplían el contacto del hombre con el paisaje, creando nuevas alternativas para la comprensión de su carácter.

La vista en la parte alta de Olinda, en la plazuela de la iglesia de la Sé, es muy bonita. Desde allá diviso el mar, las playas, la vegetación y también donde vivo. Es una tarjeta-postal. Del balcón de mi casa también 
miro el mar. El lugar fue aumentado en anchura, para proporcionar mayor comodidad, idea de mi madre (...)..$^{59}$

La vista, para el habitante, es una de las posibilidades de reconocerse en el espacio urbano, de sentirse en casa. Contribuye a acentuar ese carácter de hogar. Los miradores y los porches cumplen esa finalidad, posibilitando la práctica del ocio, principalmente en regiones de clima caliente. De la misma forma, decimos que los cobertizos o alpendres en determinados horarios del día estimulan la permanencia en sus dominios. En los quintais, simples cobertizos suelen ser denominados terrazas. Desde esos lugares, es posible acompañar el desarrollo de los tareas cotidianas realizadas en los espacios abiertos.

En la ciudad colonial, la mayoría de los conjuntos monásticos está fuertemente asociada al relieve, lo que determina la existencia de vistas panorámicas del paisaje. Esta disposición reforzaba la actitud contemplativa, hecho sutilmente puesto de manifiesto en los relatos de época, como el del Padre Fernão Cardim (1583-1590), que describe el colegio jesuita de Río de Janeiro, fundado en la colina del Castillo (c.1567). Según la concepción del religioso, el Creador actuaba como un arquitecto o pintor de extrema habilidad, para propiciar despejadas y privilegiadas vistas sobre el paisaje ${ }^{60}$.

Esta narrativa ejemplifica la vigencia de un rasgo recurrente, verificado en gran medida en los relatos inaugurales. Los primitivos núcleos de poblamiento normalmente eran emplazados en lugares que ofrecían condiciones satisfactorias de comunicación y seguridad, además de proporcionar recursos naturales adecuados, como agua y suelos fértiles, teniendo en cuenta la garantía del abastecimiento alimentario. La comprensión de tales peculiaridades demuestra que el azar no existía en el universo de las acciones administrativas. En los emprendimientos pioneros, se valoraban sobre todo los lugares con amplios panoramas ${ }^{61}$. Los conventos y monasterios que no tuvieran ese atributo corrían el riesgo de ser interpretados como mal sombreados, condición identificada en la vivienda jesuita de São Vicente (1585), de la Capitanía de São Paulo ${ }^{62}$.
La estancia en huertas/pomares y jardines, teniendo al fondo bellos panoramas, ciertamente contribuía para la elevación del espíritu de sus usuarios, lo que propiciaba sensaciones como el bienestar, algo próximo al estado de éxtasis o gracia, según el pensamiento de Nuno Mendoça $a^{63}$. Se intentaba alcanzar la comunión de los sentidos, favorecida por la vista del mar o de la montaña en las proximidades de los conjuntos construidos. Aprovechamos para destacar que, simbólicamente, se considera la montaña como "lugar para meditar, evocar Dioses, purificar cuerpo y alma". Es el lugar donde se puede experimentar el sentimiento por lo sublime, donde se manifiesta con pujanza "la espiritualidad, la religiosidad y la pureza"64. El mar, a su vez, percibido desde las cimas o desde las laderas de montañas o colinas, es un complemento de la vivienda situada literalmente en las alturas, que venía a contribuir a la alegría, placidez y sorpresa de congregados y cronistas. La superficie marítima vista desde los conventos y monasterios seducía la mirada, repetía constantemente el espectáculo de vida y fuerza y su grandiosidad indomable, lo que estimulaba la práctica de experiencias místicas ${ }^{65}$.

El valor conferido en particular a los paisajes marítimos era patente en la organización de los conjuntos concebidos, situación identificada, por ejemplo, en la disposición del Convento de Nuestra Señora de las Nieves de Olinda, fundado en 1585. En las palabras del Fray António de Santa Maria Jaboatam (1761), ese lugar sobresalía por la posición elevada y por el panorama de la $\operatorname{costa}^{66}$. Lo mismo decimos de otros complejos, como el Colegio de Bahia (1585), cuyo cercado tenía un mirador levantado sobre columnas de piedra, "abierto por todas partes", además de otros rincones, que servían de "reposos", siendo "(...) toda la recreación de este colegio, porque de él ven entrar las naos, descubren buena parte del mar ancho, y quedamos señores de todo esta concavidad, que es excelente, apacible y [tiene] desahogada vista $(\ldots)^{\prime \prime 67}$. Son datos expresivos, que sugieren la predominancia de ciertos valores inherentes a la tradición constructiva.

En Portugal, era evidente la manera en como algunas casas de campo se encontraban 


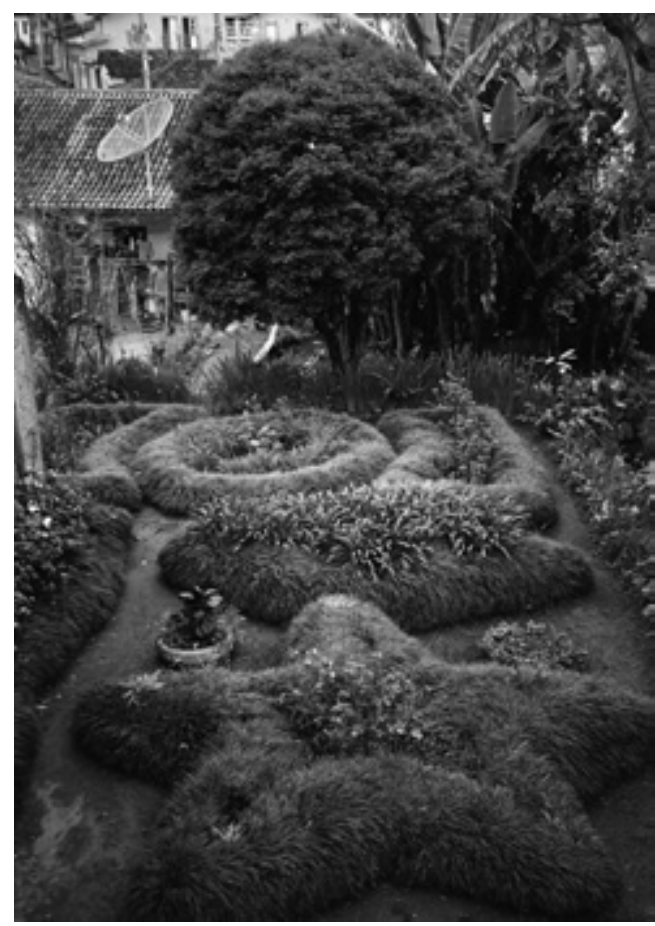

Fig. 9. Jardín contiguo al puente de Marília de Dirceu, Ouro Preto, 2006.

ordenadas, en completa sintonía con el relieve y el espacio envolvente $y / o$ el paisaje ${ }^{68}$. Lo que les importaba a los habitantes de esos lugares, más allá de la cuestión económica y productiva, era la vivencia del ocio o del estar contemplativo, aspecto eminentemente vinculado al aprovechamiento de los recursos naturales de cada lugar. Ante tales refinamientos, debemos tener precaución al trabajar con las teorías que presentan los pintores holandeses del siglo XVII, o incluso los románticos del siglo XVIII, como los precursores de una nueva sensibilidad estética relativa a la fruición de atributos de los espacios abiertos. En la práctica, en términos arquitectónicos y paisajísticos, los portugueses ya lidiaban con la mencionada temática, mucho antes de que la naturaleza fuera considerada objeto de representación pictórica. La convivencia del hombre en y con la naturaleza sucedía en espe- cial en los cercados y en las casas de campo localizadas en los arrabales.

En el dibujo de las casas de campo, sabemos que los respectivos conjuntos se mostraban estructurados por medio de la articulación de diversos subespacios, productivos y recreativos, de entre ellos los pastizales, los jardines, las huertas, los pomares y las matas, en general, distribuidos en puntos estratégicos de los terrenos, en consonancia con la topografía de cada lugar. Ciertos componentes de esas unidades aún pueden ser vistos en el interior de los primitivos tejidos de Olinda y Ouro Preto, a pesar del estado de degradación o ruina de las antiguas parcelas. Había toda una lógica de ordenamiento de esos elementos, que se conectaban a la estructura biofísica del paisaje. Maceteros, arquitecturas de placer o de holganza, bancos, pergolados o parras, que hacían apacible la 
estancia al aire libre, se localizaban, preferentemente en puntos privilegiados por la amplitud visual, en miradores y terrazas.

\section{Consideraciones finales}

Trabajar con este repertorio de elementos del paisaje contribuye a una mejor evaluación de la forma urbana y de su identidad, además de facilitar la comprensión de la espacialidad en las parcelas hortofrutícolas. Resaltamos que, en las descripciones de los habitantes que explican la existencia de vínculos con sus huertas, con sus pomares o jardines, la naturaleza se presenta viva y vivificante, siendo percibida a partir del cultivo de la tierra o incluso a través del contacto con las floraciones y las fructificacio- nes. Lo invisible gana cuerpo y revela otras dimensiones de los complejos construidos.

Ver la dimensión ecológica, estética y patrimonial en las parcelas no edificadas presupone que el observador reeduque su mirada. No hablamos de lugares excepcionales, grandiosos y monumentales, por el contrario, estamos muy próximos de aquello que es tomado como banal y perteneciente al sentido común. Por este motivo, las tipologías del tejido verde de las ciudades patrimonio, más particularmente de Olinda y Ouro Preto, no son comprendidas, en la actualidad, como objetos dignos de protección (Fig. 9), principalmente por parte de las instituciones gubernamentales, responsables de la preservación patrimonial.

\section{NOTAS}

* Traducción: Xosé Serén.

${ }^{1}$ LAMAS, José Manuel Ressano Garcia. Morfologia urbana e desenho da cidade. $2^{a}$ edición. Lisboa: Fundação Calouste Gulbenkian, Fundação para a Ciência e Tecnologia, 2000. p. $46,80$.

2 Ídem. Ibidem. p. 15.

${ }^{3}$ MENDOÇA, Nuno José de Noronha. Para uma poética da paisagem: a ideia. Évora: Universidad de Évora, 1989. v.1. p. 309, 311, 328, 335, 375. Disertación presentada a la Universidad de Évora para la obtención del Grado de Doctor en Artes y Técnicas del Paisaje. (Texto policopiado).

4 "'Imagen sin título [Planta de Olinda]'. Original manuscrito del Algemeen Rijksarchief, La Haya". In: REYES HIJO, Nestor Goulart. Imagens de vilas e cidades do Brasil colonial. São Paulo: Editora de la Universidad de São Paulo, Imprensa Oficial do Estado, Fapesp, 2000. p. 82, 331. Véase, en el volumen II, la figura $n^{\circ} 66$.

"'MARIN D'OLINDA de Pernam- buco/ T'RECIF de PERNAMBVCO'. Ilustración del libro de Johannes de Laet (LAET-1644). Ejemplar utilizado perteneciente a la Koninklijke Bibliotheek, La Haya". In: Ídem. Ibidem. p. 78,329 . Véase, en el volumen II, la figura $n^{\circ} 65$.

${ }^{5}$ NIEUHOF, Joan. Memorável viagem maritima e terrestre ao Brasil. São Paulo: Librería Martins, Taller de la Empresa Gráfica de la [Revista] de los Tribunales, [1951]. 25-26. (Edición holandesa: 1682)

KIDDER, Daniel Parish. Reminiscências de viagens e permanência no Brasil (Províncias do Norte). Colección Biblioteca Histórica Brasileña. São Paulo: Editora Livraria Martins, /s.d./. v.XII. p. 72, 74, 76, 96-99.

KOSTER, Henry, 1793-1820. Viagens ao nordeste do Brasil. $11^{\text {a }}$ edición. Recife: Fundación Joaquim Nabuco, Editora Massangana, 2002. v.1. p. 64,85 . (1 ${ }^{\text {a }}$ edición Londres: Longman, Hurst, Rees, 1816).

${ }^{6}$ KOSTER, Henry, 1793-1820. Op. cit. v.1. p. 64.

${ }^{7}$ En la lista de los bienes culturales brasileños, declarados "Patrimonio de la Humanidad", se encuentran inscritos los siguientes núcleos históricos: Ouro Preto (1980), Olinda (1982), Missões de São Miguel (1984), Salvador e Santuário de Bom Jesus de Matozinhos (1985), Brasilia (1987), São Luís (1997), Diamantina (1999), Goiás (2001). Con relación a los "sitios naturales", reconocidos por la UNESCO, se contabilizan: el Parque Nacional do Iguaçu (1986), en el Estado de Paraná; el Parque Nacional Sierra da Capivara (1991), en el Piauí; Reservas de Mata Atlántica del Sudeste, en Paraná y en São Paulo; la Costa do Descobrimento (1999), en la Bahia y en el Espirito Santo; el Complejo de Áreas Protegidas del Pantanal (2000), en el Mato Grosso; el Parque Nacional del Jaú (2000), en la Amazonia; los Parques Nacionales Chapada dos Veadeiros e das Emas (2001), en Goiás; la Reserva de Fernando de Noronha (2001), administrada por el Estado de Pernambuco y el Atol das Rocas (2001)، subordinado al Río Grande do Norte.

8 PARENT, Michel. Dosier IPHAN/UNESCO, Archivo Noronha Santos, 1967. Apud: TIRAPELI, Perci- 
val. Conhecendo os Patrimônios da Humanidade no Brasil. São Paulo: Metalivros, 2001. p. 47.

${ }^{9}$ Sobre ese asunto véase: MAGALHÃES, Manuela Zorro de. "Paisagem urbana e interface urbano-rural". In: ABREU, Margarida Cancela de (coord.). Paisagem. Colecção Estudos 2. Lisboa: DIRECÇÃO GERAL DO ORDENAMENTO DO TERRITÓRIO E DESENVOLVIMENTO URBANO. 1994. p. 111-113.

10 BUStOS ROMERO, Marta Adriana. A arquitetura bioclimática do espaço público. Brasilia: Editora da Universidade de Brasilia, 2001. p. 4655.

${ }^{11}$ VASCONCELLOS, Sylvio de. Vila Rica: formação e desenvolvimento, residências. Río de Janeiro: Ministério da Educação e Cultura, Instituto Nacional do Livro, 1956. p. 98.

12 CARAPINHA, Aurora de Concepción Parreira. "A arte da paisagem e dos jardins no Brasil colonial". In: Colóquio luso-brasileiro de história da arte, Actas, 5, Faro: Universidade do Algarve, Faculdade de Ciências Humanas e Sociais, Departamento de História, Arqueologia e Patrimônio, 2002. p. 35.

13 CARDIM, Fernão, Padre, 1548/1549-1625. Tratados da terra e gente do Brasil. Lisboa: Comissão Nacional para as Comemorações dos Descobrimentos Portugueses, 1997. p. 249-250.

${ }^{14}$ En los quintais, había animales domésticos sueltos, principalmente gallinas, utilizadas incluso en el control biológico de insectos y otras plagas que afectaban a la producción de legumbres y verduras y al cultivo de algunas especies frutícolas, como los naranjos. En esa circunstancia, se adoptaban cercas divisorias de taquara (especie de bambú brasileño), para evitar que las aves revolviesen en las eras de las hortalizas. Aún era común que existieran pequeños corrales, en lugares más alejados de la vivienda.

${ }^{15}$ Aunque la bibliografia no enfoque, con claridad, la cuestión de las servidumbres en el tejido de las ciuda- des y pueblos coloniales, es posible identificar tales aproximaciones a partir del estudio iconográfico. En la ciudad patrimonial de Ouro Preto, tuvimos la oportunidad de verificar el antiguo callejón de los "caldereros", en el barrio del Pilar, y el actual callejón del Ayuntamiento, en la plaza Tiradentes. En Olinda, posiblemente, las calles António F. Gomes, Bertiogas, Bonfim, Joaquim Cavalcante, Porto Seguro, Prudente de Moraes, São Bento y 27 de Janeiro hayan sido vías auxiliares de servicios.

HOLTHE, Jan Maurício Oliveira van. Quintais urbanos de Salvador. Realidades, usos e vivências no século XIX. Salvador: Faculdade de Arquitetura e Urbanismo da Universidade Federal da Bahia, 2002. p. 146, 150-151. Disertación de Máster en Arquitectura y Urbanismo, área de concentración en Conservación y restauración.

MOREIRA, André Renato Pina. Coordinador Adjunto del Programa Monumenta/BID, Arquitecto de la Secretaría Municipal de Planificación de la ciudad de Olinda. Entrevista sobre espaços abertos. Olinda, 2002.

RASMUSSEN, Maria de Lourdes Machado. Habitante de la ciudad patrimonial de Ouro Preto. Entrevista sobre espacios abiertos. Ouro Preto, 2006.

REIS FILHO, Nestor Goulart. Imagens de vilas e cidades do Brasil colonial. São Paulo: Editora da Universidade de São Paulo, Imprensa Oficial do Estado, Fapesp, 2000. p. 232, 257260, 278-280, 386-387, 393.

${ }^{16}$ En Ouro Preto, también es posible ver algunos puntos miradores en ciertos tramos de la trama urbana, destacándose el Alto da Cruz, las plazuelas de las iglesias de São Francisco de Assis y de São Francisco de Paula, además de las colinas del Cruzeiro, de Santana y de São Sebastião.

${ }^{17}$ CARLS, F.H. Álbum de Pernambuco e os seus arrabaldes. [Recife]: F.H. Carls, 1878. /s.p./.

" 'Marin D'Olinda de Pernambuco/ Recife de Pernambuco'. Grabado que ilustra el libro de Johannes de
Laet. c. 1630". In: REIS FILHO, Nestor Goulart. Imagens de vilas e cidades do Brasil colonial. São Paulo: Editora da Universidade de São Paulo, Imprensa Oficial do Estado, Fapesp, 2000. p. 7879, 329.

" 'Olinda'. Grabado de Frans Post, del libro de Barlaeus (1647). c.1637-1645". In: Ídem. Ibidem. p. 89, 334.

${ }^{18}$ En el cuadro de los acontecimientos históricos, podemos decir que, tras una larga fase de oscurantismo o poca visibilidad en crónicas de época, comprendida entre la invasión holandesa (1630-1654) y el inicio del ochocientos, Olinda comenzó a recuperar parte de su antiguo prestigio, perdido en favor de su vecina Recife. En medio de las transformaciones urbanas ocurridas en el siglo XIX, hubo la propagación de patrones socioculturales influidos por modismos de época, entre ellos, la promoción del hábito de tomar baños de mar y de río y poseer casas de veraneo en la ciudad. En ese sentido, nos parece oportuno reflejar otros beneficios de la vida moderna, basados en la facilidad de la obtención de alimentos, mediante la creciente práctica del comercio ambulante y de las ferias populares, hechos sobresalientes en las primeras décadas del siglo XX. En ese periodo, sucedió la ampliación de la red de abastecimiento alimentario, principalmente por la várzea del río Beberibe, que dio lugar a una mayor oferta de productos hortícolas y, posiblemente, en el gradual abandono de la subsistencia doméstica, anteriormente proporcionada por los quintais, fenómeno que interfirió en el aumento del porte de la vegetación local.

En las décadas de 1930/1940, e incluso antes del citado periodo, lo que se cultivaba en los sitios Fragoso, Jatobá, Senhor Pires y en las várzeas de los ríos Beberibe y Doce era comercializado tanto en las ferias populares (Bom Sucesso, Peixinhos, Praça da Preguiça, Sítio Novo) como en las calles de la ciudad, por vendedores ambulantes. Solamente en la década de 1950, con el 
nivel creciente de especialización de los servicios urbanos, se dio la creación de coope-rativas agrícolas, destacándose la de Vitoria de Santo Antão, localizada a 50 kilómetros de Olinda, de donde escolaba gran parte de la producción local para la atención de la demanda del citado municipio.

MELLO, José Ataíde. Funcionario jubilado del Ayuntamiento Municipal de Olinda, líder comunitario. Entrevista sobre espaços abertos. Olinda, 2005.

19 LUNA, Marília de Andrada Lacerda. Artista y residente en la ciudad patrimonial de Olinda. Entrevista sobre espaços abertos. Olinda, 2005.

Para algunos residentes de Ouro Preto, solo resta el lamento ante el proceso de degradación del paisaje. "Mirar con ojos sensibles de la cultura y de la historia nos lleva a llorar de saudade. La ciudad está perdiéndose. Tierra es aquella que nosotros escogemos y amamos, tristemente, se ha convertido en madrastra (...)".

SIMÕES, José Feliciano da Costa. Párroco de la Matriz del Pilar y residente de la ciudad patrimonial de Ouro Preto. Entrevista sobre espaços abertos. Ouro Preto, 2003.

${ }^{20}$ BUSTOS ROMERO, Marta Adriana. A arquitetura bioclimática do espaço público. Brasilia: Editora da Universidade de Brasilia, 2001. p. 94-95.

21 "El quintal es para mi el universo del miedo, de la aventura y descubrimiento. Es también el lugar del recogimiento, además de ser agradable y aireado. Me siento bien en contacto con otros seres vivos. Me gusta plantar (...)".

CUNHA, Petrônio. Arquitecto de la Secretaría Municipal de Planificación y vecino de la ciudad patrimonial de Olinda. Entrevista sobre espaços abertos. Olinda, 2005.

${ }^{22}$ DÍAS, Genoveva Alves. Artista y residente de la ciudad patrimonial de Olinda. Entrevista sobre espaços abertos. Olinda, 2005.

${ }^{23}$ LAROZE, Catherine. Une histoire sensuelle des jardines. France: Oli- vier Orban, 1990. p. 15-18.

MENDOÇA, Nuno José de Noronha. Para uma poética da paisagem: a ideia. Évora: Universidade de Évora, 1989. v.1. p. 183-186. Disertación presentada a la Universidad de Évora para la obtención del Grado de Doctor en Artes y Técnicas del Paisaje. (Texto multicopiado).

${ }^{24}$ OLIVEIRA, Ana Amélia Lopes de. Artista y residente en la ciudad patrimonial de Ouro Preto. Entrevista sobre espaços abertos. Ouro Preto, 2006.

${ }^{25}$ LAROZE, Catherine. Une histoire sensuelle des jardines. France: Olivier Orban, 1990. p. 18, 24, 34-35, 53.

${ }^{26}$ SIMÕES, José Feliciano de la Costa. Párroco de la Matriz del Pilar y vecino de la ciudad patrimonial de Ouro Preto. Entrevista sobre espaços abertos. Ouro Preto, 2003.

27 "(...) En Ouro Preto el paisaje olfativo es muy importante. La ciudad exhalaba no solamente perfumes, sino que también tenía sus olores desagradables. Me acuerdo cuando era quemada la candeia [vegetación típica de la región] en los fogones de leña (...). El olor aromatiza el lugar. Eso dejó de suceder con la aparición de fogones a gas. Si, por un lado, a la vegetación nativa se les ahorró cortes, por otro, la ciudad perdió uno de sus olores característicos, además de ser periódicamente invadida por mosquitos (...)"

DELFIN, Carlos Fernando de Moura. Arquitecto Paisajista. Técnico en Defensa y Preservación Ambiental. Asesor Especial de la $6^{\text {a Regional del }}$ Instituto del Patrimonio Histórico y Artístico Nacional, IPHAN/Río de Janeiro. Entrevista sobre espaços abertos. Belo Horizonte, 2005.

${ }^{28}$ Para engrandecer la realización de la solemnidad específica en la capilla de Nuestra Señora de los Dolores, en Ouro Preto, durante el viernes de la Semana Santa, se forraba el piso de la nave con ramos de alecrín y albahaca (blanca) que, al ser macerados con los pies, exhalaban con intensidad sus respectivos aromas.

LISBOA, Carlos Eduardo. Profesor de Botánica, Universidad Federal de Ouro Preto, UFOP. Entrevista sobre espaços abertos. Ouro Preto, 2006.

${ }^{29}$ REGO, Teresa Costa. Artista y residente de la ciudad patrimonial de Olinda. Entrevista sobre espaços abertos. Olinda, 2005.

${ }^{30}$ DÍAS, Genoveva Alves. Artista y residente de la ciudad patrimonial de Olinda. Entrevista sobre espaços abertos. Olinda, 2005

${ }^{31}$ CARAPINHA, Aurora de Concepción Parreira. Da essência do jardim português. Évora: Universidade de Évora, 1995. p. 68-69. Disertación de Doctorado en Arquitectura Paisajista y Arte de los Jardines, Ramo de Artes y Técnicas del Paisaje. (Texto multicopiado).

32 NORBERG-SCHULZ, Christian Genius Loci. Paysage, Ambience, Architecture. [Bruxelles, Liége]: Pierre Mardaga éditeur, [1981]. p. 14 [Edición original: 1976].

${ }^{33}$ FERREIRA, Aurélio Buarque de Holanda. Novo dicionário Aurélio da língua portuguesa. $3^{a}$ edición. Curitiba: Positivo, 2004. p. 1237

${ }^{34} \mathrm{LYNCH}$, Kevin. Planificación del sitio. Barcelona: Editorial Gustavo Gili, 1980. p. 172. (Primera edición de 1977).

${ }^{35}$ FERREIRA, Aurélio Buarque de Holanda. Op. cit. p. 548

36 PENA FILHO, Carlos. "Olinda". In: VILAÇA, Marcos Vinícios. Olinda, Olindissima. Brasilia: Fundación Nacional PróMemória, 1983. p. 21.

En consonancia con Gilberto Freyre, no se puede considerar Olinda sin hablar sobre su luz. "(...) Para [Joaquim] Nabuco, la belleza de Pernambuco venía principalmente de su luz. Todo lo que él exalta, en página célebre, en el paisaje de Pernambuco, en general, $y$ en el de Olinda, en particular, es efecto de la luz: el cielo que no es el mismo un minuto; el mar que está siempre cambiando de color; 'el brillo metálico del plumero del cocotero'; 'la sombra demorada de los árboles de Jack y mangos.' (...)".

FREYRE, Gilberto. Olinda, $2^{\circ}$ Guia Prático, Histórico e Sentimental de 
Cidade Brasileira. $4^{a}$ edición. Río de Janeiro: Librería José Olympio Editora, 1968. p. 16, 18.

${ }^{37}$ Situado en la porción centro-sur del Estado de Minas Gerais, el municipio de Ouro Preto, mapeado a partir de las coordenadas $20^{\circ} 30^{\prime}$ de latitud sur y 443' de longitud oeste, presenta altitud media de $1.100 \mathrm{~m}$. Más allá de estas peculiaridades, el clima de la región, en consonancia con la tabla de Köpen, corresponde al del tipo Cwb tropical de altitud con veranos suaves, lluvias en el verano e invierno seco. La temperatura media varía de $18^{\circ}$ a $20^{\circ} \mathrm{C}$. Las mayores precipitaciones ocurren de enero a febrero y las medias anuales quedan en torno a 1.400 $1.600 \mathrm{~mm}$. Esta región de Minas, por la conformación de su relieve, es tenida como superhúmeda. Con relación a los vientos, predominan los desplazamientos de las masas de aire en la dirección Este-Oeste/Oeste, y situaciones de calma.

La M\&CONSULTORES ASOCIADOS. Ouro Preto. Relatório final. Belo Horizonte: Servicio de Apoyo a las Micro y Pequeñas Empresas de Minas Gerais, SEBRAE, Sistema de Informação Mercadológicas Municipales, 1995. p. 7-10

BRASIL. MEC; IPHAN; IEPHA; FUNDACIÓN JOÃO PINHEIRO. Plano de conservação, valorização e desenvolvimento de Ouro Preto e Mariana. Belo Horizonte: Fundación João Pinheiro, 1975. p. 5.

${ }^{38}$ MEIRELES, Cecília. "Escenario". In: MEIRELES, Cecília. Romanceiro da Inconfidência. $3^{a}$ edición. Río de Janeiro: Editora Civilização Brasileira, 1977. p. 57.

${ }^{39}$ MOREIRA, André Renato Pina. Coordinador Adjunto del Programa Monumenta/BID, Arquitecto de la Secretaría Municipal de Planificación de la ciudad de Olinda. Entrevista sobre espaços abertos. Olinda, 2002.

${ }^{40}$ HOLANDA, Armando de. Roteiro para construir no Nordeste. Arquitetura como lugar ameno nos trópicos ensolarados. Recife: Programa en Desarrollo Urbano de la Facultad de
Arquitectura, UFPE, 1976. p. 9, 11, 15, 31, 33, 39, 42 .

${ }^{41}$ Todas las donaciones, de carácter productivo y recreativo, fueron citadas a partir de hechos conocidos en las Capitanías de Pernambuco, Tamaracá y Paraíba, localizadas en la Región Nordeste brasileña, durante el siglo XVII.

BRANDÃO, Ambrósio Fernandes. Diálogos das grandezas do Brasil. Recife: Fundación Joaquim Nabuco, Editora Massangana, 1997. p. 130. (Texto datado en el segundo semestre de 1618).

${ }^{42}$ CARAPINHA, Aurora de Concepción Parreira. Da essência do jardim português. Évora: Universidade de Évora, 1995. v.1. p. 302, 304, 308, 311. Disertación de Doctorado en Arquitectura Paisajista y Arte de los Jardines, Rama de Artes y Técnicas del Paisaje. (Texto multicopiado).

${ }^{43}$ ADB-CSB. Mosteiro de Nossa Senhora da Graça, 1717-1789. p. 36. Apud: LINS, Eugênio de Ávila. Arquitectura dos mosteiros beneditinos no Brasil: século XVI a XIX. Porto: Universidad de Oporto, Facultad de Letras, Departamento de Ciencias y Técnicas del Patrimonio, 2002. v.l. p. 880 . Tesis de Doctorado en Historia del Arte. (Texto multicopiado).

${ }^{44}$ HABSBURGO, Maximiliano de. Bahia 1860. Esboços de viagem. Rio de Janeiro: Tempo Brasileiro; Bahia: Fundación Cultural del Estado de la Bahia, 1982. p. 125. Apud: HOLTHE, Jan Maurício Oliveira van. Quintais urbanos de Salvador. Realidades, usos e vivências no século XIX. Salvador: Facultad de Arquitectura y Urbanismo de la Universidad Federal de la Bahia, 2002. p. 189. Disertación de Máster en Arquitectura y Urbanismo, área de concentración en Conservación y Restauro.

Para el americano Samuel Greene Arnold, que visitó Bahia en 1847, "el mango era el rey de los trópicos, muy grande y frondoso como un roble, con denso follaje verde oscuro y hoja de la forma del laurel (...)".

ARNOLD, Samuel Greene. /s.t./: /s.n.t, [188?]. /s.p./. Apud: HOLTHE, Jan
Maurício Oliveira van. Op. cit. p. 189.

45 "Lo que hace la gran belleza de este nuestro pedazo de tierra pernambucano es en primer lugar su cielo, que cambia cada instante, leve, puro, suave, donde las nubes parecen tener alas, y que no es el mismo en un minuto; es después nuestro mar, verde, vibrátil y luminoso, nuestras arenas templadas y cubiertas de hierba, nuestros cocos, que impregnan desde el zócalo hasta el plumero de un brillo metálico y dorado, con que parecen a lo lejos sacudir las nubes blancas, los árboles de jack y los mangos cuya sombra redonda es un oasis de frescura y abundancia (...)" (subrayado nuestro).

NABUCO, Joaquim. "Ramalho Ortigão no Recife". In: GOUVÊA, Fernando de la Cruz. Perfil del tiempo. Recife: Fundación de Cultura Ciudad del Recife, 1990. p. 169-173. [Publicado en el periódico el "Paiz" de 30/11/1887]. Apud: SOUTO MAYOR, Mário; SILVA, Leonardo (orgs.). A paisagem pernambucana. Recife: FUNDAJ, Editora Massangana, Secretaría de Educación, Cultura y Deportes, 1993. p. XLVI.

${ }^{46}$ Sentada bajo la sombra de una carambola, Eulina Guedes Amâncio, residente de la ciudad patrimonial de Olinda, describe con cariño las plantas que conserva en su jardín. Son conocidas popularmente por el nombre en clave de ervas-de-banho. Al comentar pausadamente sobre el local y sus componentes, justifica el empeño para su conservación, diciendo: "quién tiene vida, da vida". El ambiente de ese espacio está marcado por la sensación refrescante de aromas, sombreados y vistas, teniendo al fondo la imagen imponente del conjunto arquitectónico franciscano, bien delineado contra el verde de la vegetación y el azul del mar. Esta residente compara su jardín a una sala de estar, en donde se puede acompañar el movimiento de la calle y las variaciones del ambiente del lugar.

AMÂNCIO, Eulina Guedes. Habitante de la ciudad patrimonial de la 
ciudad de Olinda. Entrevista sobre espaços abertos. Olinda, 2005.

${ }^{47}$ Con relación al clima de Olinda, la temperatura media es de $26,3^{\circ} \mathrm{C}$. La pluviosidad se sitúa en torno de 1.900 a 2.000 milímetros anuales, correspondiendo al tipo Asi, según la clasificación de Köppen.

NOVAES, Ferdinando. Olinda, Evolução urbana. Recife: FUNDARPE, 1990. p. 9-10.

48 BARRETO, Vicente; VALENÇA, Alceu. "Morena tropicana". In: COSTA, Paloma Jorge Amado. As frutas de Jorge Amado ou o livro de delicias de Fadul Abdala. São Paulo: Companhia das letras, 1997. p. 7.

"En 'Tieta do Agreste' están todas las frutas que se pueda imaginar, y todos los derivados de ellas también, del agua-de-coco al queimado de guayaba. Desfilan ante los lectores las frutas frescas en sus variedades, los sorbetes, los dulces de pasta, los de almíbar, las secas, las sabias y los refrescos, los licores, los batidos, las bananas-fritas y las frutas-pan cocidas. Tieta es golosa — si ella fuese una fruta sería todas ellas-, pero no es avara, las reparte con los amigos, reparte también su conocimiento, enseña a Leonora las diferencias entre araçá y guayaba, entre piña y condesa, lo que es jaca-de-pobre, el porqué del nombre del dulce de banana de rodinha. La hartura es tanta en Santana do Agreste que Perpétua se queja con Tieta de que los mendigos no aceptan frutas como limosna: 'No aceptan ni mangos, ni cajus, dicen que nadie los compra, que tienen de más, mango no es limosna que se de, ya oyó?'"

COSTA, Paloma Jorge Amado. As frutas de Jorge Amado ou o livro de delícias de Fadul Abdala. São Paulo: Companhia das letras, 1997. p. 19-20.

${ }^{49}$ MELO, Almeri Bezerra de. Director del Centro Interuniversitario de Estudios de América Latina, África y Asia, filósofo/sociólogo, residente de la ciudad patrimonial de Olinda. Entrevista sobre espaços abertos. Olinda, 2002.

${ }^{50}$ AHU. Colección Iconografia, 8 dibujos, E.D., Anónimo, "Frutos tropi- cais: ananás, bananeira, cajueiro, dendezeiro, fruteira do conde, goiabeira, mamoeiro, maracujazeiro". /s.d./. Manuscritos acuarelados. $275 \times 435$ mm (dimensión media).

${ }^{51}$ LAROZE, Catherine. Une histoire sensuelle des jardines. France: Olivier Orban, 1990.p. 45-47, 51, 62.

${ }^{52}$ SCHAEFER, Carlos Ernesto et al. "Elementos da paisagem e a gestão da qualidade ambiental". Informe agropecuário. Agropecuária e Ambiente. Belo Horizonte: EPAMIG, v.21, n 202, p. 23-25, Ene./Feb. 2000.

${ }^{53}$ NIEUHOF, Joan. Memorável viagem marítima e terrestre ao Brasil. São Paulo: Livraria Martins, Oficina da Empresa Gráfica da [Revista] dos Tribunais, [1951]. p. 25-26. (Edición holandesa: 1682).

SAINT-HILAIRE, Auguste de. Viagem pelas províncias do Rio de Janeiro e Minas Gerais. Belo Horizonte: Editora Itatiaia; São Paulo: Editora da Universidade de São Paulo, 1975. p. 70. (Edición francesa: 1830).

LIMA JÚNIOR, Augusto de. A capitania de Minas Gerais. [3ª] edición. Belo Horizonte: Editora Itatiaia; São Paulo: Editora de la Universidad de São Paulo, 1978. Prefácio de Jaime Cortesão. p. 11

${ }^{54}$ OLIVEIRA, Ana Amélia Lopes de. Artista y residente de la ciudad patrimonial de Ouro Preto. Entrevista sobre espaços abertos. Ouro Preto, 2006.

55 MENEZES, José Luiz Moto. "Olinda: evolução urbana". In: CARITA, Helder; ARAÚJO, Renata (coords.). Colectânea de estudos. Universo urbanístico português 1415-1822. Lisboa: Comissão Nacional para as Comemorações dos Descobrimentos portugueses, 1998. p. 338.

${ }^{56}$ Lo que sucede es algo muy cercano a lo que Nuno Mendoça denomina de percepción global o relacional del espacio, manifestándose de manera continua, multidireccional y múltiple.

MENDOÇA, Nuno José de Noronha. Para uma poética da paisagem: a ideia. Évora: Universidade de Évora, 1989. v.1. p. 34-37, 308, 314. Disertación presentada a la Universidad de Évora para obtención del Grado de Doctor en Artes y Técnicas del Paisaje. (Texto multicopiado).

${ }^{57}$ MOREIRA, Mariana Isabel. Funcionaria de la Secretaría Municipal de Educación de la ciudad de Ouro Preto. Entrevista sobre espaços abertos. Ouro Preto, 2006.

${ }^{58}$ Conviene esclarecer que, según la cultura brasileña, se comprende el término varanda como azotea y/o terraza. Ese lugar era relacionado con la vivencia del placer u ocio. Como espacio de placidez en la vivienda, el balcón se destinaba a las comidas, siendo propicia también a devaneos musicales y poéticos, que manifestaban encantamientos y saudades. La visión que se usufructuaba en ese dominio estimulaba los sentidos, lo que nos remite al construir frondoso, de Armando de Holanda, visualizado en la obra de Albert Eckhout, cuyo examen nos hace considerar la articulación entre los edificios y los jardines coloniales.

Cf. CORONA, Eduardo; LEMOS, Carlos A.C. Dicionário da arquitetura brasileira. São Paulo: Edart, 1972. p. 468.

59 RAMOS, Madalena de Barros Lima. Residente de la ciudad patrimonial de Olinda. Entrevista sobre espaços abertos. Olinda, 2005.

${ }^{60}$ Las situaciones de belleza natural, anotadas en los registros efectuados, en especial conectadas al mencionado Colegio, posiblemente causaban una mezcla de admiración y sorpresa incluso en los incrédulos, que deberían sentirse compelidos a descubrir o redescubrir las dimensiones cualitativas de tan grandiosa obra. En el siglo $\mathrm{XVI}$, se divulgó el lugar de la siguiente manera:

"La ciudad [de Río de Janeiro] está situada en un monte [colina de Castillo de San Sebastián] de buena vista para el mar, y dentro de la barra tiene una bahía que bien parece que la pintó el supremo pintor y arquitec- 
to del mundo Dios Nuestro Señor, $y$ asi es cosa hermosisima y la más apacible que hay en todo el Brasil, ni le llega la vista del Mondego y Tajo; es tan capaz que tendrá 20 leguas en rueda llena por el medio de muchas islas frescas de grandes arbolados, y no impiden la vista unas a las otras que es lo que le da gracia. (...) / Los padres tienen aquí el mejor sitio de la ciudad. Tienen gran vista con toda esta ensenada enfrente de las ventanas: han comenzado el edificio nuevo, tienen ya 13 cubículos de piedra y cal que dan ventaja a los de Coimbra, antes se la llevan en la buena vista. (...) El cercado es cosa hermosa; tiene muchos más naranjos que los dos cercados de Évora, con un tanque y fuente; pero no se bebe de ella por el agua ser salobre; muchos membri-llos, granados, limeros y otros frutos de la tierra. También tiene una viña que da buenas uvas, los melones se dan en el refectorio casi medio año, y son finos, ni faltan berzas mercianas bien duras, lechugas, rabanos y otros géneros de hortaliza de Portugal en abundancia: el refectorio está bien provisto de lo necesario; la vaca en la bondad y gordura se parece a la de Entre-Douro y Minho; el pescado es vario y mucho, son para ver las pesquerías del viernes, (...) Dudaba yo cual era más provisto, si el refectorio de Coimbra si este, y no me sé determinar: en cuanto al espiritual se parece en la observancia, buen concierto y orden con cualquiera de los bien ordenados de Portugal (...)".

CARDIM, Fernão, Padre, 1548/1549-1625. Tratados da terra e gente do Brasil. Lisboa: Comissão Nacional para as Comemorações dos Descobrimentos Portugueses, 1997. p. 267-269.

${ }^{61}$ ACADEMIA BRASILEIRA. Cartas jesuíticas; cartas avulsas (1550-1568). Rio de Janeiro: Oficina Industrial Gráfica, 1931. p. 313, 315-316, 347. Apud: LEITE, Serafim, Padre. História da Companhia de Jesus no Brasil; a obra, século XVI. Lisboa: Livraria Portugália; Rio de Janeiro: Civilização Brasileira, 1938b. Tomo II. p. 56.

62 CARDIM, Fernão, Padre, 1548/1549-1625. Op. cit. p. 276.

63 MENDOÇA, Nuno José de Noronha. Para uma poética da paisagem: a ideia. Évora: Universidade de Évora, 1989. v.1. p. 62, 98, 101-103. Disertación presentada a la Universidad de Évora para obtención del Grado de Doctor en Artes y Técnicas del Paisaje. (Texto multicopiado).

${ }^{64}$ Ídem. Ibidem. 1989. v.1. p. 95.

65 CHEVALIER, Jean; GHEERBRANT, Alain. Dicionários dos símbolos: mitos, sonhos, costumes, gestos, formas, figuras, cores, números. [Lisboa]: Círculo de Leitores, 1997. p. 4146, 439.

MENDOÇA, Nuno José de Noronha. Op. cit. v.1. p. 106-107, 109, 114.
${ }^{66}$ JABOATAM, António de Santa Maria, Frei. Orbe serafico novo brasilico. Lisboa: Officina de Antonio Vicente da Silva, 1761. Libro I. p. 250.

67 CARDIM, Fernão, Padre, 1548/1549-1625. Tratados da terra e gente do Brasil. Lisboa: Comissão Nacional para as Comemorações dos Descobrimentos Portugueses, 1997. p. 279.

En otras circunstancias, los miradores se incorporaban a los edificios, pasando a tener ventanas con balcones para el mar o el río, conforme sucedió en las sedes de los Monasterios de Nuestra Señora de Brotas (1777/1780) y de Nuestra Señora de la Gracia, situados en los alrededores de la ciudad de Salvador.

ADB-CSB. Códice 143. Monasterio de Nuestra Señora de la Gracia, 1717-1789. p. 37. Apud: LINS, Eugênio de Ávila. Arquitectura dos mosteiros beneditinos no Brasil: sécuIo XVI a XIX. Oporto: Universidad de Oporto, Facultad de Letras, Departamento de Ciencias y Técnicas del Patrimonio, 2002. v.l. p. 884. Tesis de Doctorado en Historia del Arte. (Texto multicopiado).

${ }^{68}$ ARAÚJO, llídio Alves de. Arte paisagista e arte dos jardins em Portugal. Lisboa: Dirección general de los Servicios de Urbanización, 1962. v.1. p. $102,129-130,135,141,155,159-$ 162, 184, 188, 200, 203, 207-215, 223. 